\title{
TRATAMENTO SUPERFICIAL DE PEÇAS FABRICADAS POR PROTOTIPAGEM RÁPIDA
}

Felipe Borges Feliciano de Lima

DISSERTAÇÃO DE MESTRADO EM CIÊNCIAS MECÂNICAS

\section{UNIVERSIDADE DE BRASÍLIA}

FACULDADE DE TECNOLOGIA

DEPARTAMENTO DE ENGENHARIA MECÂNICA 
UNIVERSIDADE DE BRASÍLIA

FACULDADE DE TECNOLOGIA

DEPARTAMENTO DE ENGENHARIA MECÂNICA

PROGRAMA DE PÓS-GRADUAÇÃO EM CIÊNCIAS MECÂNICAS

TRATAMENTO SUPERFICIAL DE PEÇAS FABRICADAS POR PROTOTIPAGEM RÁPIDA

FELIPE BORGES FELICIANO DE LIMA

ORIENTADOR: TAYGOARA FELAMINGO DE OLIVEIRA DISSERTAÇÃO DE MESTRADO EM CIÊNCIAS MECÂNICAS PUBLICAÇÃO: ENM.DM - 231A/2015

BRASÍLIA/DF: JULHO - 2015 


\author{
UNIVERSIDADE DE BRASÍLIA \\ FACULDADE DE TECNOLOGIA \\ DEPARTAMENTO DE ENGENHARIA MECÂNICA
}

\title{
TRATAMENTO SUPERFICIAL DE PEÇAS FABRICADAS POR PROTOTIPAGEM RÁPIDA
}

Felipe Borges Feliciano de Lima

DISSERTAÇÃO SUBMETIDA AO DEPARTAMENTO DE ENGENHARIA MECÂNICA DA FACULDADE DE TECNOLOGIA DA UNIVERSIDADE DE BRASÍLIA COMO PARTE DOS REQUISITOS NECESSÁRIOS PARA A OBTENÇÃO DO GRAU DE MESTRE EM CIÊNCIAS MECÂNICAS.

Aprovada por:

Taygoara Felamingo de Oliveira, Prof. Dr., UnB

(Orientador)

Adriano Todorovic Fabro, Prof. Dr., UnB

(Examinador Interno)

Suzana Moreira Ávila, Prof. Dra., UnB - FGA

(Examinadora Externa)

Brasília-DF, 16 de julho de 2015. 


\section{FICHA CATALOGRÁFICA}

DE LIMA, FELIPE BORGES FELICIANO

TRATAMENTO SUPERFICIAL DE PEÇAS FABRICADAS POR PROTOTIPAGEM RÁPIDA

vii, 54p., 210x297 mm (EnM/FT/UnB, Mestre, Ciências Mecânicas, 2015)

Dissertação de Mestrado - Universidade de Brasília.

Faculdade de Tecnologia.

Departamento de Engenharia Mecânica.
1. Manufatura Aditiva
2. Pós-tratamentos
3. Rugosidade superficial
4. FDM
I. EnM/FT/UnB
II. Título (ENM.DM - 231A/2015)

\section{REFERÊNCIA BIBLIOGRÁFICA}

BORGES, F. B. F. L., (2015) Tratamento superficial de peças fabricadas por prototipagem rápida. Dissertação de mestrado, Publicação ENM.DM-231A/2015, Departamento de Engenharia Mecânica, Universidade de Brasília, 54p.

\section{CESSÃO DE DIREITOS}

NOME DO AUTOR: Felipe Borges Feliciano de Lima.

TÍTULO DA DISSERTAÇÃO DE MESTRADO: TRATAMENTO SUPERFICIAL DE PEÇAS FABRICADAS POR PROTOTIPAGEM RÁPIDA.

GRAU/ANO: Mestre/2015

É concedida à Universidade de Brasília permissão para reproduzir cópias desta tese de mestrado e para emprestar ou vender tais cópias somente para propósitos acadêmicos e científicos. O autor reserva outros direitos de publicação e nenhuma parte desta dissertação de mestrado pode ser reproduzida sem a autorização por escrito do autor.

Felipe Borges Feliciano de Lima

SQS 116 Bloco J, Apartamento 312 - Asa Sul

70.386-100 Brasília - DF - Brasil

felipeborgesfl@gmail.com 


\section{RESUMO}

Apesar de agora serem populares e acessíveis para pequenos laboratórios, empresas e hobbystas, a qualidade superficial das peças fabricadas através de FDM - Fused Deposition Modelling ainda não é satisfatória para grande parte dos propósitos de utilização da tecnologia. Ainda que novas abordagens nas técnicas de slicing e processamento das peças estejam sendo empregadas, o acabamento manual das mesmas ainda é necessário. Outros métodos de pós-processamento das peças ainda são caros e pouco práticos. Este trabalho propõe e compara métodos de pós-processamento de peças impressas em ABS - Acrilonitrila Butadieno Estireno com o uso de Dimetilcetona (Acetona). A rugosidade superficial foi previamente medida em diversos corpos de prova que foram submetidas a quatro técnicas diferentes de tratamento, por diferentes períodos de tempo. As técnicas utilizadas foram: imersão em uma solução aquosa de acetona, exposição ao vapor de acetona em um recipiente hermético à $21^{\circ} \mathrm{C}$, a $50^{\circ} \mathrm{C}$ e após o ponto de ebulição da acetona. Os resultados do trabalho são curvas de evolução da rugosidade superficial da peça com respeito ao tempo de aplicação do pós-tratamento. Os principais achados do trabalho são que estes tratamento são processos controláveis e com resultados previsíveis e que podem produzir reduções de rugosidade na ordem de 1000\%

\footnotetext{
ABSTRACT

Despite now being popular and affordable to small laboratories, companies and hobbyists, the surface quality of the parts produced through FDM - Fused Deposition Modeling are not yet satisfactory for a wide range of purposes. Even tough new approaches on model slicing and processing are being employed, hand finishing of the parts is still necessary. Other post-processing methods are not practical and expensive. This work proposes and compare methods of chemical post processing of Acrylonitrile Butadiene Styrene ABS printed parts with the use of dimethyl-ketone (acetone). Surface roughness was previously measured for several test artifacts that were then submitted to four different techniques of treatment for different periods. The techniques used were immersion in a acetone water solution; exposure to acetone vapor in a closed vessel, at $21^{\circ} \mathrm{C}, 50^{\circ} \mathrm{C}$ and after the boiling point. The results are curves with the reduction of surface roughness with respect to post treatment duration for the different methods. The main finding is that this is a somewhat controllable process with predictable results and that produces reductions in surface roughness in the order of the $1000 \%$.
} 


\section{SUMÁRIO}

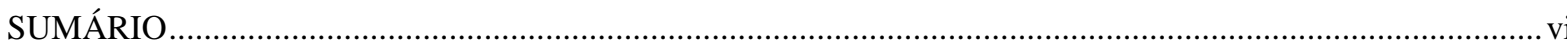

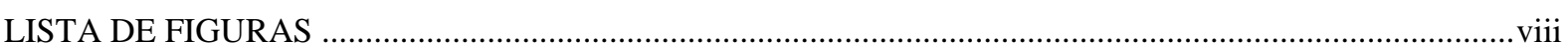

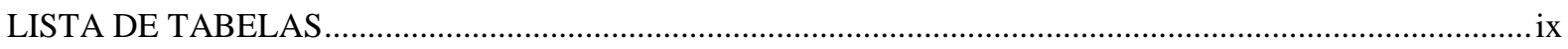

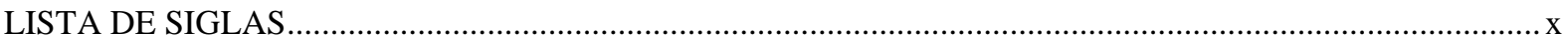

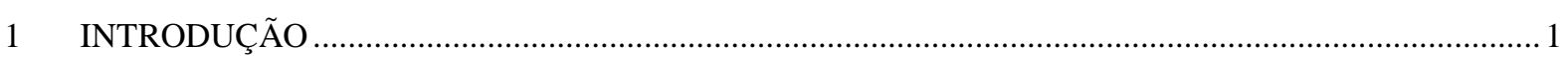

1.1 HISTÓRICO DA TECNOLOGIA E CONTEXTUALIZAÇÃO DO TRABALHO ............................2

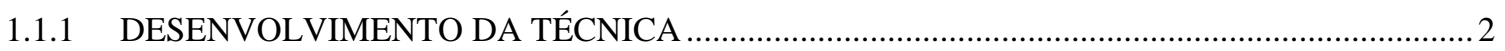

1.1.2 FUNCIONAMENTO DE UMA IMPRESSORA DO TIPO FDM .............................................. 3

1.1.3 CARACTERÍSTICAS DAS PEÇAS FABRICADAS POR FDM ............................................. 4

1.1.4 ESFORÇOS PARA MELHORIA NA QUALIDADE DAS PEÇAS ........................................ 6

1.1.5 PÓS-TRATAMENTO QUÍMICO DE PECAS ........................................................................ 8

1.1.6 MÉTODOS DE APLICAÇÃO DO SOLVENTE NA PEÇA ..................................................... 9

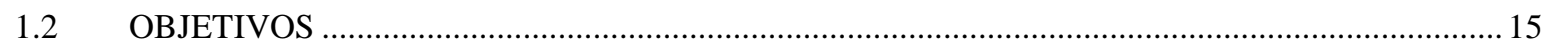

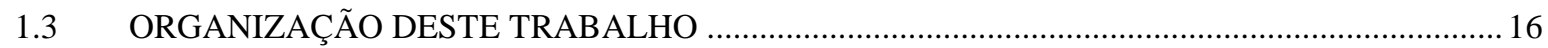

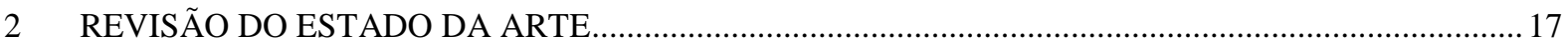

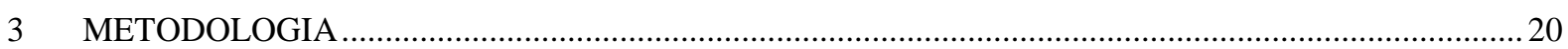

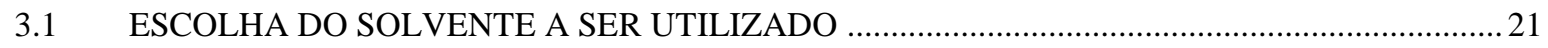

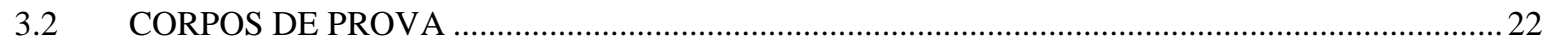

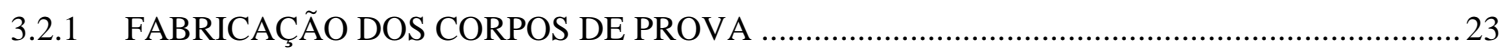

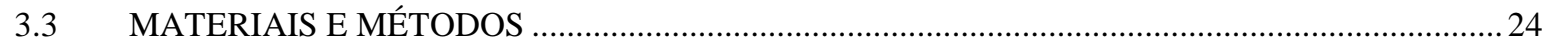

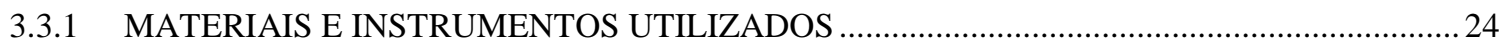

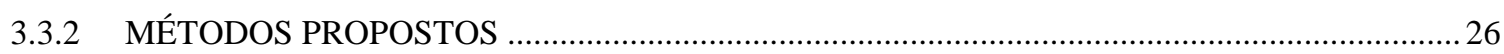

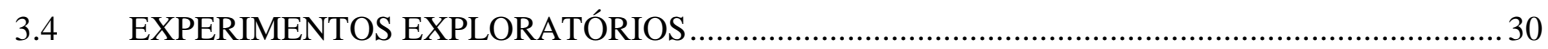

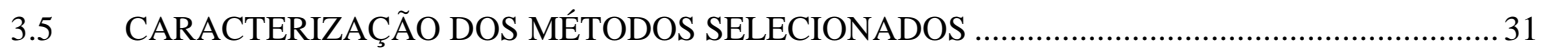

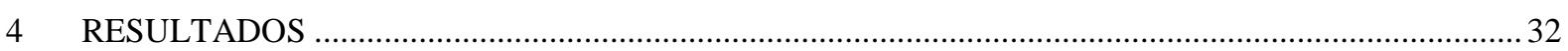

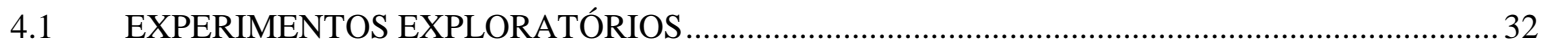

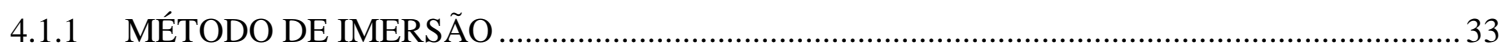

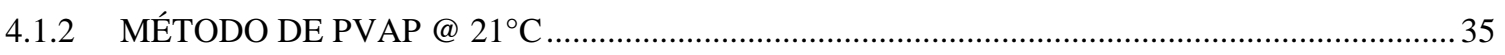

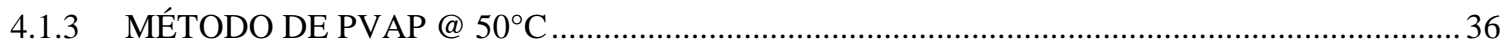

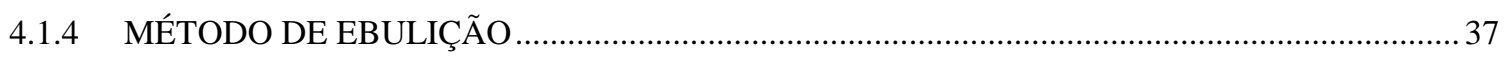

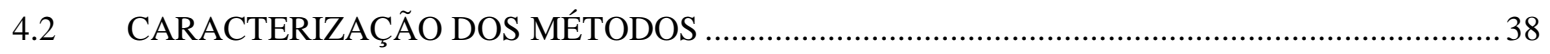

4.2.1 CONFIGURAÇÃO E CALIBRAÇÃO DO INSTRUMENTO DE MEDIDA ..............................39

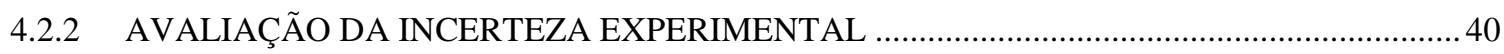

4.2.3 MEDIÇÃO INICIAL DA RUGOSIDADE DOS CPS E ANÁLISE DOS RESULTADOS .......... 41

4.2.4 CARACTERIZAÇÃO DO MÉTODO DE IMERSÃO ...............................................................43

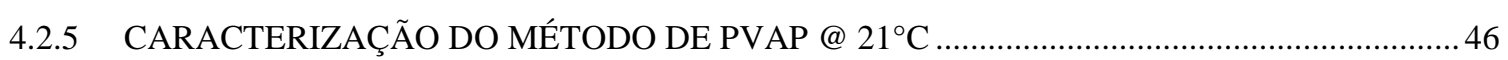

4.2.6 CARACTERIZAÇÃO DO MÉTODO DE EBULIÇÃO ….....................................................49

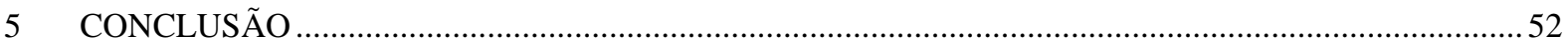




\section{LISTA DE FIGURAS}

Figura 1- Funcionamento de uma impressora 3D do tipo FDM. Traduzido de: http://www.spiegel.de/fotostrecke/photo-gallery-printing-your-own-pistol-fotostrecke-97636.html. ................. 3 Figura 2- Camadas em uma peça fabricada via FDM. Fonte: http://xy-kao.com/sandbox/layer-heights-on-the-3d-

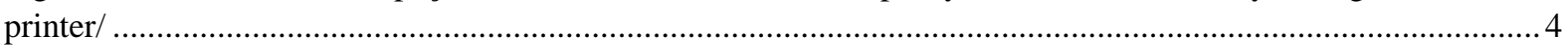
Figura 3 - Exemplos de falhas em Overhangs. Fonte: https://innovationstation.utexas.edu/tip-design................4 Figura 4 - Representação do Staircase Effect. Traduzida de: http://nptel.ac.in/courses/Webcourse-contents/IITDelhi/Computer\%20Aided\%20Design\%20\&\%20ManufacturingII/Module\%20G/Module\%20G(4)/p4.htm .......5 Figura 5 - Exemplo de uso de material de suporte. Traduzida de: http://3dpunlimited.com/using-supportstructures-3d-printing/.

Figura 6 - Stratasys Finishing Touch. Fonte: http://www.stratasys.com/3d-printers/finishing-touch-smoothingstation

Figura 7 - Estação de tratamento Magic Box. Fonte: https://www.kickstarter.com/projects/magicbox/magicboxmagically-finish-your-3d-prints/description....

Figura 8 - Exemplo de arranjo com uso de uma panela elétrica. Fonte: http://www.instructables.com/id/QualityFinish-3D-Prints-with-Acetone/.

Figura 9 - Exemplo de tratamento utilizando uma mesa aquecida e água em ebulição para controle da temperatura. Fonte:http://sinkhacks.com/building-acetone-vapor-bath-smoothing-3d-printed-parts/............... 12 Figura 10- Exemplo de aparato que utiliza a mesa aquecida de uma impressora 3D open Source. Fonte: http://blog.reprap.org/2013/02/vapor-treating-abs-rp-parts.html.......................................................... 12 Figura 11 - Sistema de tratamento com recuperação do vapor de acetona. Traduzido de: http://www.soliforum.com/topic/183/diy-smoothing-station/. ................................................................ 13 Figura 12- Exemplo de sistema de pós-tratamento com imersão em acetona líquida proposto em plataforma de financiamento coletivo. Fonte: https://www.kickstarter.com/projects/1809448130/3d-refiner-by-

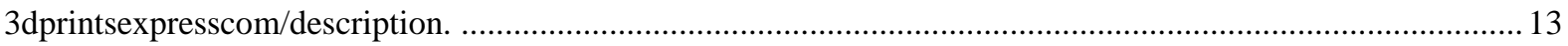
Figura 13 - Método de tratamento com vapor de acetona gerado em temperatura ambiente. Fonte: http://airwolf3d.com/2013/11/26/7-steps-shiny-finish-on-abs-parts-acetone/. ........................................ 14

Figura 14- Fluxograma da investigação proposta................................................................................ 20

Figura 15- Modelo do CP proposto, com as dimensões retratadas em mm. ...............................................22

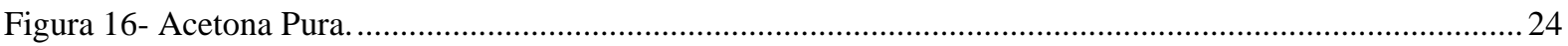

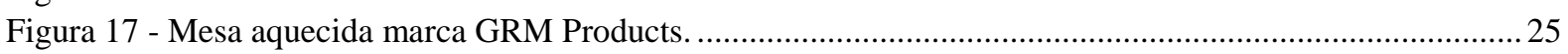

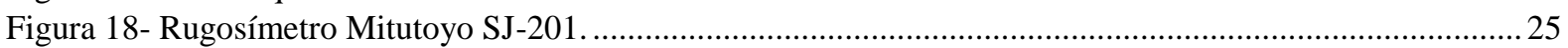

Figura 19- Representação do aparato experimental de imersão........................................................................26

Figura 20 - Representação do aparato experimental de ebulição................................................................22

Figura 21 - Representação do aparato experimental de Pvap @ $21^{\circ} \mathrm{C}$. ............................................................28

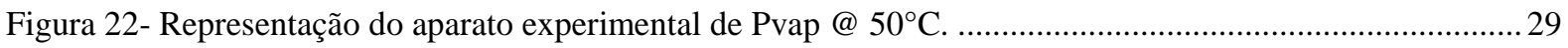

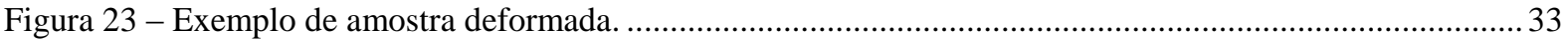

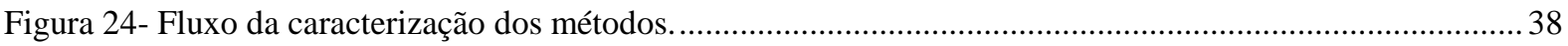

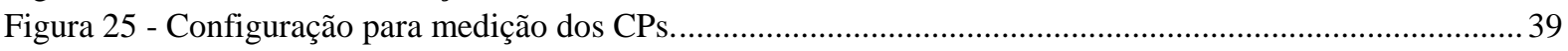

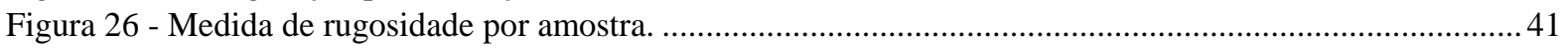

Figura 27 - Medidas de rugosidade para amostras ordenadas por ordem crescente de rugosidade. ....................42

Figura 28 - Resultados da caracterização do método de imersão. .................................................................44

Figura 29 - Representação da saturação da acetona em contato com o CP...................................................44

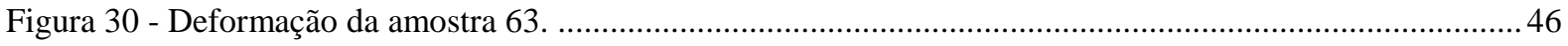

Figura 31 - Resultados da caracterização do método de Pvap @ $21^{\circ} \mathrm{C}$. ...........................................................4 47

Figura 32 - Resultados da caracterização do método de ebulição. ...............................................................50 


\section{LISTA DE TABELAS}

Tabela 1- Métodos de Pós-Tratamento, retirado e traduzido de (9)

Tabela 2 - Resultados do experimento exploratório em imersão.......

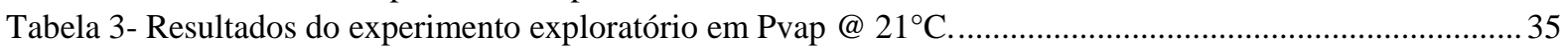

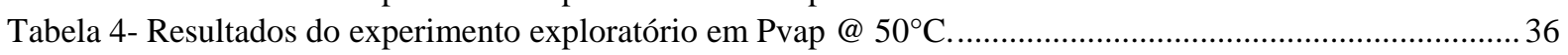

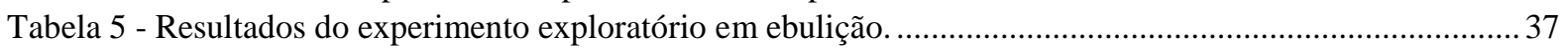

Tabela 6 - Resumo das medidas de avaliação da incerteza experimental. ...........................................................40

Tabela 7- Resumo dos ensaios de caracterização do método de imersão. ......................................................43

Tabela 8 - Resumo dos ensaios de caracterização do método de Pvap @ 21 ${ }^{\circ} \mathrm{C}$...................................................46

Tabela 9 - Resumo dos ensaios de caracterização do método de ebulição ........................................................49 


\section{LISTA DE SIGLAS}

ABS - Acrilonitrila Butadieno Estireno

CP - Corpo de Prova

FDM - Fused Deposition Modelling

HIPS - High Impact Polystyrene 


\section{INTRODUÇÃO}

Com a recente popularização das tecnologias da impressoras 3D, várias classes de usuários foram beneficiadas com a capacidade de se fabricar peças em pequena escala e com um grau aceitável de qualidade. Entre os beneficiados com a novidade estão os entusiastas de tecnologia, as empresas de desenvolvimento de produtos, designers, artistas, engenheiros e em grande peso também o setor educacional.

Junto da maturação da tecnologia, surgem também demandas relacionadas a melhoria da interação do usuário com a tecnologia e dos resultados obtidos na utilização da mesma. Em suma, os usuários esperam cada vez mais qualidade nas peças fabricadas e mais facilidade no uso das ferramentas.

Estas demandas tem sido atacadas em várias frentes: melhorias de software, hardware, na mecânica das máquinas, nas técnicas de modelagem e fatiamento (slicing) das peças, na interface de uso, em dispositivos para gestão de filas de impressão, novos materiais e filamentos entre diversos outros.

Atuando nestas melhorias estão diversos setores da tecnologia e conhecimento: empresas, universidades, governos e principalmente uma legião de entusiastas.

Dentre as abordagens para a melhoria da qualidade das peças, está a temática deste trabalho: os processos de pós-tratamento das peças impressas. O nível de acabamento atingido e a complexidade da técnica utilizada variam em um grande espectro intimamente associados ao custo e ao grau de automação da técnica utilizada.

Estão disponíveis hoje desde técnicas manuais de acabamento como o emassamento, lixamento e pintura até a sofisticações como a usinagem das peças em centros robotizados seguido de uma metalização à vácuo.

Na parte mais simples do espectro, aonde se encontram as técnicas manuais e de baixo custo encontrase uma incompatibilidade com o nível de facilidade e automação do processo atingido pela tecnologia de manufatura aditiva. Requer-se uma grande especialização do usuário para se obter um bom acabamento e a repetibilidade do processo manual é baixa.

Na parte mais complexa do espectro se encontra um descompasso entre o custo e a complexidade de se operar o maquinário para realização do acabamento da peça com a redução de custo e complexidade observadas no mercado de impressoras 3D para uso geral.

A barreira tecnológica para os processos de pós-tratamento agora se encontra em como compatibilizar a qualidade do acabamento atingido com o custo, complexidade e repetibilidade da técnica.

Para isto se propõe neste trabalho o estudo das técnicas de pós-tratamento químico de peças plásticas, que têm grande potencial em diminuir a interação do usuário com o processo e produzir resultados de alta qualidade com um aparato simples e robusto. 


\subsection{HISTÓRICO DA TECNOLOGIA E CONTEXTUALIZAÇÃO DO TRABALHO}

\subsubsection{DESENVOLVIMENTO DA TÉCNICA}

As técnicas de fabricação aditiva, desde sua introdução nos anos 80, vem carregadas de uma aura futurista e no passado recente tem permeado a imaginação de vários setores da sociedade com as possibilidades que carrega.

Inicialmente desenvolvida para finalidades de prototipagem rápida, a manufatura aditiva evoluiu em termos de métodos e técnicas e hoje é capaz de operar em regime de produção industrial em uma miríade de setores, fabricando peças de diversos materiais - plásticos, cerâmicas, metais, tecidos orgânicos, fibras, etc. com precisões e velocidade de produção cada vez maiores e custos menores, geralmente associados a maturação da tecnologia.

O universo de possibilidades de técnicas, métodos e materiais disponíveis para cada cenário de uso é bem tratado na literatura técnica e científica. Um bom apanhado pode ser encontrado no trabalho de Pham e Gault (1) que categoriza os processos de manufatura aditiva de acordo com critérios de materiais e processos e apresenta um fluxograma de decisão para a escolha de métodos de fabricação aditiva baseado nas demandas de resultado final.

Além dos equipamentos industriais de grande porte, velocidade e ultimamente custo, nos últimos anos viu-se popularizar as impressoras 3D desktop acessíveis aos usuários não profissionais, para fabricação de peças plásticas on site.

Essa tendência da popularização da fabricação de poucas unidades, pelo usuário final, assistido por softwares de projeto e fabricação é conhecida como Fabricação Digital (2). Este tópico é bastante atual e vêm sido discutido dentro de diversas comunidades, como por exemplo no movimento Maker; entre designers; engenheiros; grandes empresas de software de projeto como a Autodesk e seu Pier 9; laboratórios de institutos renomados como o The Center for Bits and Atoms do MIT entre vários outros.

Definimos aqui não profissionais aqueles que a atividade fim não é a própria fabricação aditiva ou a prototipagem rápida, mas aqueles que usam a tecnologia como ferramenta, seja para desenvolvimento, validação de modelos, hobby, fins de pesquisa científica, etc.

Podemos associar essa popularização a um marco específico, que foi a queda da patente (3) que protegia a tecnologia de impressão 3D denominada FDM - Fused Deposition Modelling, ou em tradução livre, modelagem por deposição de material fundido, que é a tecnologia foco deste trabalho.

Com a queda da patente, entusiastas da tecnologia puderam projetar e disponibilizar de forma aberta Open Source - todo o necessário para que interessados trabalhem e melhorem todos os aspectos de uma impressora FDM de pequeno porte e baixo custo. Como no projeto conhecido como RepRap (4), que é de imenso sucesso e pode ser associado diretamente ao momento atual no campo das impressoras 3D domésticas voltadas ao consumidor.

A abertura do projeto em todos os seus aspectos - hardware, firmware, software e projeto mecânico facilita a adesão de novos usuários ao projeto que passam a participar ativamente no desenvolvimento da tecnologia.

O desenvolvimento da tecnologia aliado ao maior número de usuários acaba sendo percebido em projetos de equipamentos mais elegantes, de menor custo e que fazem uso da economia de escala para facilitar a fabricação e sourcing de componentes e reduzir ainda mais o custo.

Cada uma dessas forças contribui para o aumento das outras em um ciclo de desenvolvimento contínuo, que hoje está levando a tecnologia a um patamar de maturidade, padronização de componentes críticos, redução de custos, robustez no trabalho e melhoria de qualidade das máquinas e peças fabricadas. 


\subsubsection{FUNCIONAMENTO DE UMA IMPRESSORA DO TIPO FDM}

A Figura 1Figura 1 representa de forma conceitual o funcionamento de uma impressora FDM.

\section{Por dentro de uma impressora 3D Como funciona uma impressora FDM}

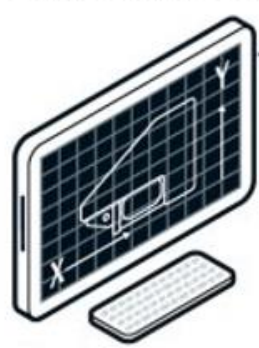

1. Um computador processa um arquivo com estrutura do objeto desejado e inicia o processo de impressão.

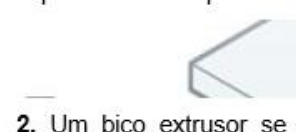
move nas direções horizontais sobre uma plataforma de trabalho de altura ajustável.

4. A plataforma afunda 0 equivalente a uma camada após a construção de cada camada, e na sequência o bico começa a aplicar a camada seguinte.

Um segundo bico extrusor contendo um material que pode ou não ser diferente do primeiro é utilizado para criar uma estrutura de suporte descartável, que permitirá a construção de estruturas em overhang.

Figura 1- Funcionamento de uma impressora 3D do tipo FDM. Traduzido de: http://www.spiegel.de/fotostrecke/photogallery-printing-your-own-pistol-fotostrecke-97636.html.

Primeiramente um modelo 3D da peça a ser fabricado é interpretado por um software que realiza o slicing ou fatiamento da peça, para que a mesma possa ser fabricada camada a camada. A espessura de camada é um dos parâmetros chave na fabricação das peças e está associada à qualidade final da peça e a velocidade de fabricação.

Na sequência o software gera um conjunto de instruções de trabalho para a impressora, que a partir daí imprime uma camada e realiza a movimentação da mesa de trabalho para que se imprima a camada subsequente sobre a anterior.

A deposição de material se dá através de uma cabeça de impressão que se movimenta dentro de um plano de trabalho. Nesta cabeça estão um ou mais bicos de impressão (extrusores) que fazem a fusão do material plástico - fornecido em carretéis de filamentos - e depositam o material fundido nas posições determinadas pelo software.

Em máquinas com múltiplos extrusores é possível se usar mais de uma combinação de filamentos: mesmo material mas com cores diferentes ou mais de um material por peça.

O processo de impressão em camadas tem características inerentes que afetam a aparência das peças fabricadas e as geometrias que podem ser fabricada sem o uso de artifícios. Na sequência serão mostradas as peculiaridades da técnica que afetam o acabamento final da peça e as soluções utilizadas para mitigação das mesmas. 


\subsubsection{CARACTERÍSTICAS DAS PEÇAS FABRICADAS POR FDM}

O primeiro efeito visível da fabricação por FDM é a possibilidade de se visualizar na peça a interface entre cada camada, como mostrado na Figura 2.

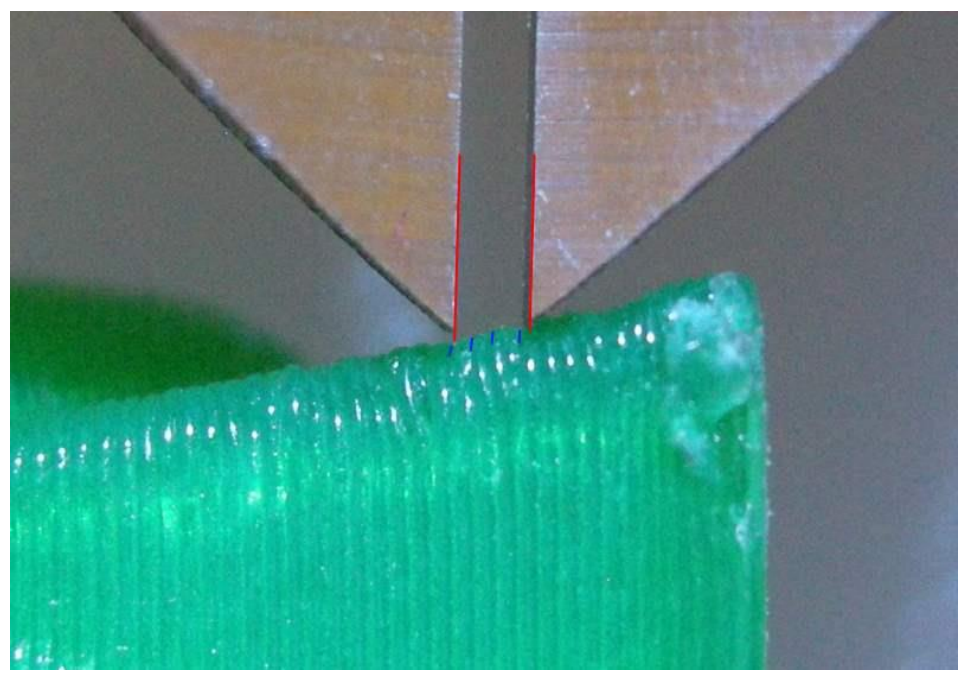

Figura 2- Camadas em uma peça fabricada via FDM. Fonte: http://xy-kao.com/sandbox/layer-heights-on-the-3d-printer/

Neste caso, quanto mais espessas as camadas, mais visível o efeito. Logo, a solução lógica para o problema é a redução da espessura de camada (5) cujo limite inferior ultimamente está relacionado a questões construtivas das próprias máquinas. Para garantir a qualidade das peças fabricadas, é preciso que a impressora seja capaz de manter um distanciamento preciso e constante entre o plano de impressão e os bicos extrusores a fim de se obter camadas uniformes.

As outras duas principais características relacionadas a sobreposição de camadas que afetam diretamente a qualidade do acabamento das mesmas são conhecidos como staircase effects e os overhangs effects.

Overhangs são estruturas proeminentes em relação a peça que não possuem uma transição suave de geometria, criando uma descontinuidade entre camadas e por consequência uma impossibilidade de impressão.

A Figura 3 exemplifica este tipo de falha ou que em certos arranjos se torna uma característica que gera uma impossibilidade de impressão da peça.

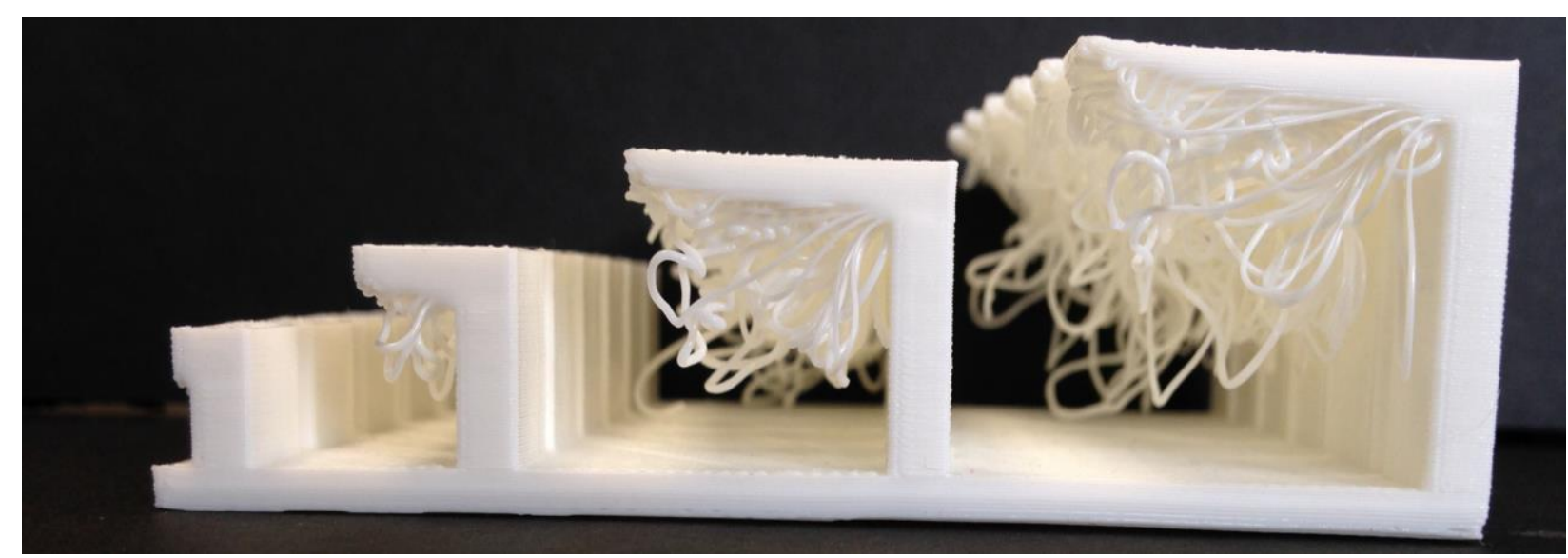

Figura 3 - Exemplos de falhas em Overhangs. Fonte: https://innovationstation.utexas.edu/tip-design

A medida em que a projeção da peça aumenta, as camadas iniciais são depositadas no ar, e tendem a solidificar de forma aleatória. Conforme se depositam mais camadas, a estrutura volta a convergir para a forma original, se apoiando nas camadas falhas. Existem contextos, ao contrário do observado na Figura 3, que a peça final fica totalmente descaracterizada devido à impossibilidade da impressão do overhang. 
O segundo efeito mencionado, o staircase effect ou efeito de escadaria, é visível quando há um pequeno deslocamento entre camadas, como por exemplo para se fabricar uma face curva ou inclinada, como mostrado na Figura 4.

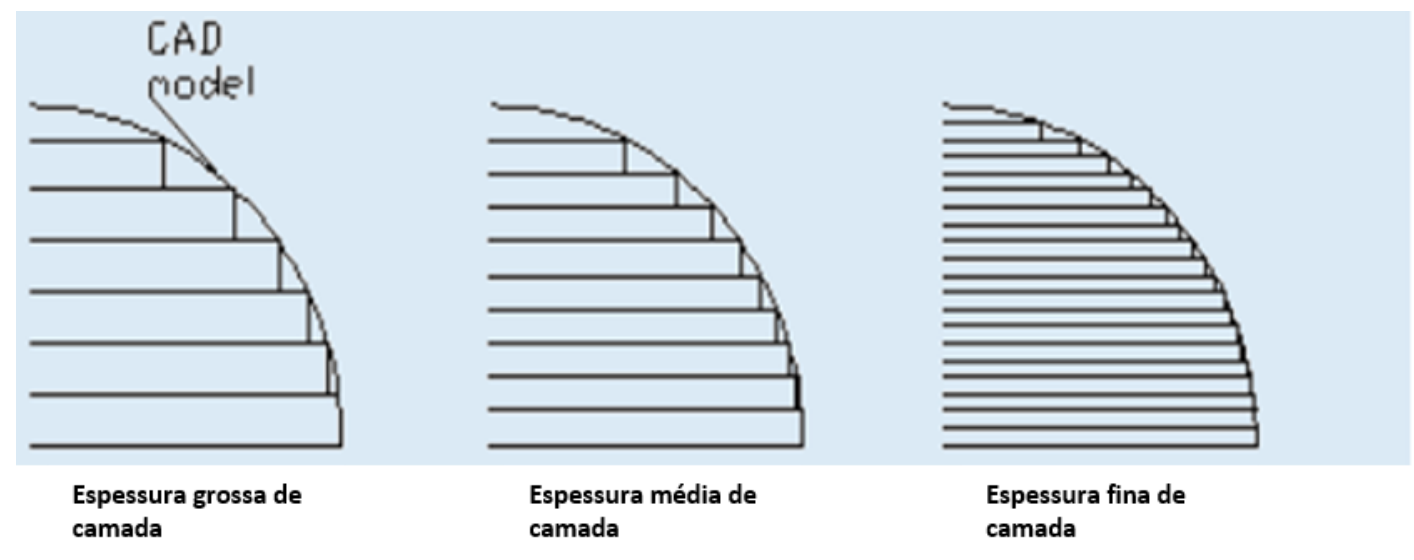

Figura 4 - Representação do Staircase Effect. Traduzida de: http://nptel.ac.in/courses/Webcourse-contents/IITDelhi/Computer\%20Aided\%20Design\%20\&\%20ManufacturingII/Module\%20G/Module\%20G(4)/p4.htm

O efeito pode ser entendido como uma aproximação de curvas feito por segmentos de reta. Quanto menores os segmentos de reta utilizados, neste caso entendidos como a espessura de camada, mais fiel ao formato real da curva ou peça o ajuste será.

Os fenômenos associados à fabricação em camadas são, como mostrados aqui, simples de serem visualizados e compreendidos como origem de falhas na qualidade superficial das peças. Na seção subsequente, serão abordadas as estratégias que podem ser usadas para mitigar os efeitos percebidos nas peças fabricadas. 


\subsubsection{ESFORÇOS PARA MELHORIA NA QUALIDADE DAS PEÇAS}

As características citadas anteriormente, que são inerentes ao processo de impressão em camadas, podem ser contornadas com o uso de algumas estratégias, que estão sendo abordadas em diversas frentes, tanto na indústria quanto na academia e também entre a comunidade de usuários da tecnologia.

Em relação a redução das espessura de camadas, que em geral aumenta a qualidade das peças e diminui a intensidade do staircase effects, a primeira frente de pontos passíveis de melhorias está relacionada à qualidade construtiva das próprias máquinas. Podemos aqui citar como pontos de melhoria utilizados o uso de peças de precisão para os conjuntos de movimentação da máquina, o aumento da rigidez da estrutura das mesmas, a mitigação de vibrações, o aumento da estabilidade e qualidade do conjunto extrusor, entre outros.

No trabalho de Chen e Lu (5) é analisado o comportamento da qualidade superficial das peças à medida em que se reduz a espessura de camada. Observou-se que dentro de uma faixa de valores de espessura de camada a qualidade superficial da peça está diretamente ligada a redução da mesma.

Verificou-se também que a partir de uma certa espessura de camada, a escolha de uma orientação otimizada de fabricação da peça passa a ser mais relevante do que uma redução ainda maior da camada.

A otimização de escolha da orientação da peça na superfície de trabalho da máquina é extensamente abordada pela comunidade acadêmica, juntamente com a seleção de parâmetros otimizados e de estratégias de análise da peça para construção do caminho dos extrusores de plástico e serão abordados na seção deste trabalho denominada Revisão do Estado da Arte.

Em relação aos overhangs, quando possível, tenta-se atacar o projeto da peça a fim de se evitarem geometrias desfavoráveis ao uso da técnica de FDM, como protrusões longas e transições não-suaves no contorno externo da peça.

Caso seja inviável mudar o projeto da peça, busca-se primeiramente uma da orientação da peça que minimize a ocorrência de estruturas longas sem suporte ou que se projetem para fora da peça. Um exemplo claro disso seria trocar a orientação da peça da Figura 5 para que a mesma fosse construída no plano de trabalho, ao invés de perpendicular ao mesmo.

Nos casos em que as abordagens anteriores não sejam viáveis ou suficientes, é feito o uso de estruturas de suporte, que são removidas ao final da fabricação da peça, para construção das geometrias em overhang. A Figura 5 exemplifica o uso de suportes em diversas situações.

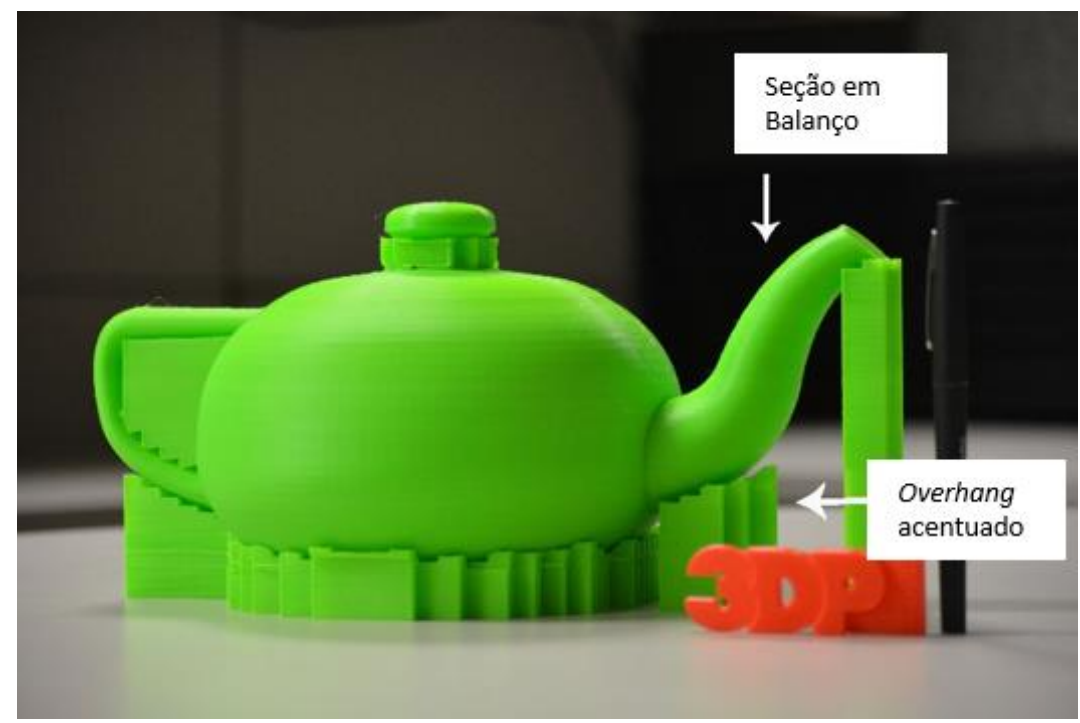

Figura 5 - Exemplo de uso de material de suporte. Traduzida de: http://3dpunlimited.com/using-support-structures-3dprinting/

Pode-se notar o uso de suportes internos à geometria da peça para viabilizar a impressão de estruturas em protrusão, como a alça do bule; ou com transições não suaves, como na tampa do bule.

São usados também suportes que partem da superfície de trabalho da máquina em direção a peça, para apoiar partes da mesma que fazem um ângulo acentuado com a vertical. É interessante notar que no bico do 
bule, devido à variação na geometria, existem partes em que se necessita do suporte e outras aonde não, a depender do ângulo mencionado anteriormente.

Com a evolução dos softwares de impressão, o algoritmo de geração de suportes embutidos nos mesmos foi otimizado a fim de se reduzir a quantidade de material necessário e a adesão do suporte a peça impressa. Desta forma, a remoção do suporte é facilitada e deixam-se menos marcas na superfície da peça.

Outra técnica utilizada em impressoras com múltiplos extrusores, é o uso de um material de suporte diferente do material da peça. Desta forma, pode-se diluir o material de suporte sem afetar a peça fabricada. Quando assim, deve-se usar um par de plásticos adequados, como por exemplo ABS - Acrilonitrila Butadieno Estireno como material base e HIPS - High Impact Polystyrene como material de suporte solúvel em limoneno.

Após fabricada a peça e removidos os suportes, caso seja necessário melhorar o acabamento superficial da peça, podem ser aplicadas as técnicas de pós-tratamento. Estão disponíveis para tal desde técnicas simples e manuais - como o lixamento da peça - ao uso de maquinário extremamente rebuscado para usinagem com fluido abrasivo ou metalização à vácuo das peças, por exemplo.

A quantidade e diversidade de técnicas disponíveis para tal é extensa e o assunto é tratado com mais profundidade na seção referente ao Estado da Arte. O ponto relevante para este trabalho, é que dentro do espectro de técnicas de pós-tratamento disponíveis há uma descontinuidade entre o custo/complexidade e a qualidade do resultado final.

Técnicas simples e de baixo custo trazem resultados com baixa repetibilidade e demandam um alto grau de habilidade do operador da técnica enquanto técnicas com alta repetibilidade e automação tem o custo muito elevado.

Desta forma, os usuários beneficiados com a popularização das impressoras 3D ainda estão distantes de um método de acabamento das peças fabricadas que seja ao mesmo tempo de baixo custo, alta efetividade e que não demande habilidades específicas do usuário.

Uma abordagem promissora para atuar nesta descontinuidade é o desenvolvimento do uso de solventes para realização do acabamento das peças plásticas. O conceito envolve expor a superfície da peça a um solvente que homogeneíze a mesma suavizando a transição entre camadas. A próxima seção trata especificamente sobre o assunto, mostrando as abordagens já utilizadas. 


\subsubsection{PÓS-TRATAMENTO QUÍMICO DE PECAS}

O uso de solventes no acabamento final de peças fabricadas via FDM já é utilizado, apesar da pouca literatura científica no tema.

Estão disponíveis hoje alguns sistemas comerciais e vários usuários da tecnologia propuseram métodos próprios para a realização dos tratamentos.

Devido à questões de solubilidade, o plástico que pode ser utilizado nos casos encontrados é o ABS que pode ser dissolvido em uma gama de solventes comerciais de baixa toxicidade e alta disponibilidade.

Outros plásticos comumente utilizados para em impressoras do tipo FDM são solúveis apenas em substâncias tóxicas, de venda controlada ou de custo elevado, tornando pouco viável a utilização dos mesmo focada na subsequente aplicação do pós-tratamento.

O conceito do tratamento se baseia na dissolução da superfície da peça fabricada de forma que as camadas se fundam de forma homogênea.

Para a realização do tratamento podem ser usados vários métodos de aplicação de solvente na peça, que são mostrados nas seções a seguir com exemplos de casos reais de utilização. 


\subsubsection{MÉTODOS DE APLICAÇÃO DO SOLVENTE NA PEÇA}

Para a escolha dos métodos de aplicação a serem analisados neste trabalho, foram utilizadas várias fontes de possíveis soluções.

Entre elas estão os padrões comerciais utilizados, os experimentos realizados pela comunidade Open Source e também os trabalhos na comunidade acadêmica.

Cita-se brevemente aqui alguns dos exemplos para se contextualizar o cenário atual de possibilidades sendo abordadas.

\section{- Métodos comerciais}

Possivelmente o equipamento mais conhecido para pós tratamento em peças impressas em ABS é fornecido também por uma das maiores fabricante de equipamentos e fornecedora de soluções para manufatura aditiva, a Stratasys.

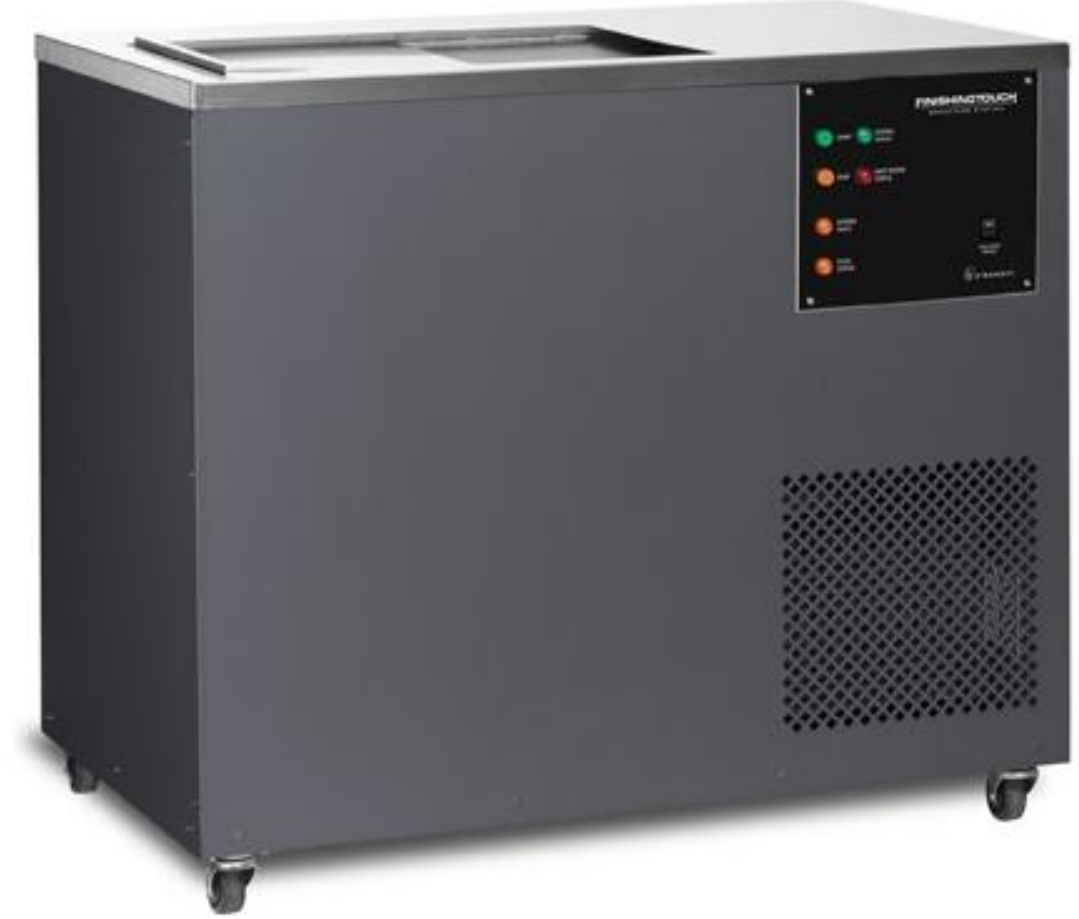

Figura 6 - Stratasys Finishing Touch. Fonte: http://www.stratasys.com/3d-printers/finishing-touch-smoothing-station

O equipamento, mostrado na Figura 6, é composto por duas câmaras, uma aquecida e uma resfriada na qual peça inicia o tratamento, para que a sua temperatura seja reduzida e ajude na condensação do vapor de solvente ao ser transferida para a câmara aquecida. Nesta, a peça é exposta a uma atmosfera de vapor do solvente - gerado por ebulição do mesmo - e devido a diferença de temperatura entre a peça (já resfriada) e o vapor, uma fina camada do solvente se forma sobre a peça, que é removida desta câmara e levada novamente para a câmara resfriada, para que haja a cura da mesma.

A crítica é que mesmo este sendo um equipamento profissional de alto custo, há uma grande necessidade de envolvimento do operador no processo, avaliando o acabamento obtido e se reaplicando o tratamento caso necessário, e também no grande tempo de cura da peça, geralmente entre 12 e 18 horas (6).

Este equipamento é um bom exemplo do que não é objetivo deste trabalho: alto custo inicial, uso de solvente proprietário e de custo elevado, alto grau de envolvimento do operador e necessidade de conhecimentos específicos do mesmo, elevado tempo de tratamento e tecnologia patenteada.

Todos esses pontos contribuem negativamente para a disseminação da tecnologia entre os usuários que se beneficiaram da popularização das impressoras 3D. 
Um outro exemplo de equipamento comercial mais alinhado com as necessidades dos novos usuários é a Magic Box, fornecida pela Taiwanesa Sky Tech e mostrada na Figura 7. A versão inicial do equipamento foi financiada através de uma plataforma de financiamento coletivo.

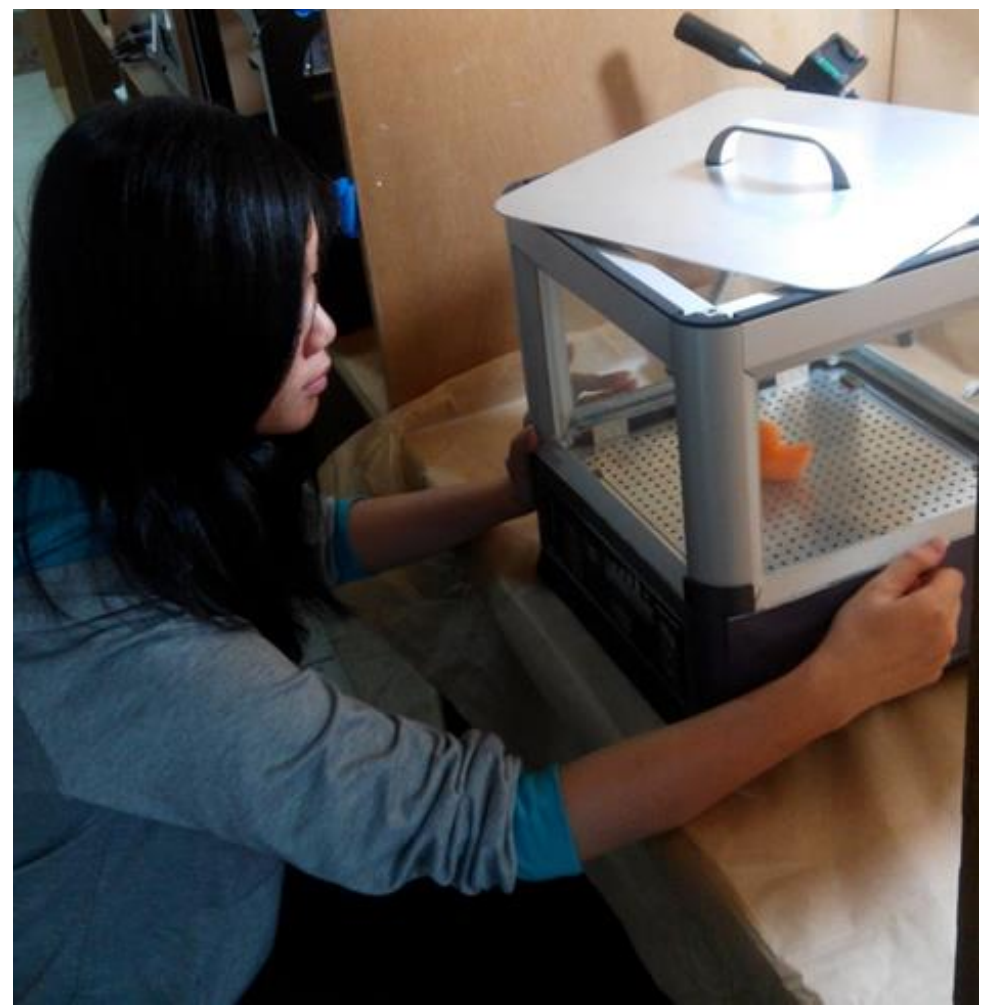

Figura 7 - Estação de tratamento Magic Box. Fonte: https://www.kickstarter.com/projects/magicbox/magicbox-magicallyfinish-your-3d-prints/description

Neste equipamento a peça é exposta ao vapor de acetona, e o mesmo permite um controle qualitativo da quantidade de vapor gerada e do tempo de tratamento.

$\mathrm{O}$ recipiente é hermético e o equipamento controla a pressão interna de acetona para que não haja vazamento e o usuário seja exposto desnecessariamente. Além disso, um sistema de exaustor e filtro faz a remoção do restante de vapor de acetona ao final do ciclo de tratamento.

O equipamento fornece ao usuário indicadores visuais do nível de acetona, tempo restante de tratamento e opções selecionadas para o ciclo, sendo assim simples de operar, aparentemente segura e fornecendo um certo grau de controle do resultado a ser obtido. 


\section{- Métodos encontrados na literatura científica}

Existem poucos trabalhos dentro da temática na comunidade científica, dos quais podemos destacar o trabalho (6) realizado pelo grupo formado dos pesquisadores Gianluca Percoco, Fulvio Lavecchia e Luigi Maria Galantucci, do Politécnico de Bari, na Itália.

O grupo em questão realizou experimentos de caracterização de um tratamento baseado na imersão de peças fabricadas em ABS em uma solução aquosa de acetona.

Os resultados analisados tratam tanto da melhoria do acabamento superficial das peças, avaliados em relação à rugosidade da peça, quanto as propriedades mecânicas das peças.

Este tópico é tratado em detalhes na seção da revisão do estado da arte.

\section{- Métodos encontrados na comunidade de entusiastas ou em projetos de financiamento coletivo}

Dentro da comunidade de entusiastas se encontram facilmente diversos métodos empíricos para a realização de tratamentos superficiais com acetona com aparatos que variam dos níveis mais simples de complexidade até a equipamentos com recuperação do vapor de acetona.

Nos exemplos encontrados, o foco do tratamento é sempre a aparência visual da peça em detrimento do controle da rugosidade superficial e da estabilidade dimensional da peça, que não é conferida pelos proponentes dos métodos.

A seguir se mostram exemplos de arranjos encontrados.

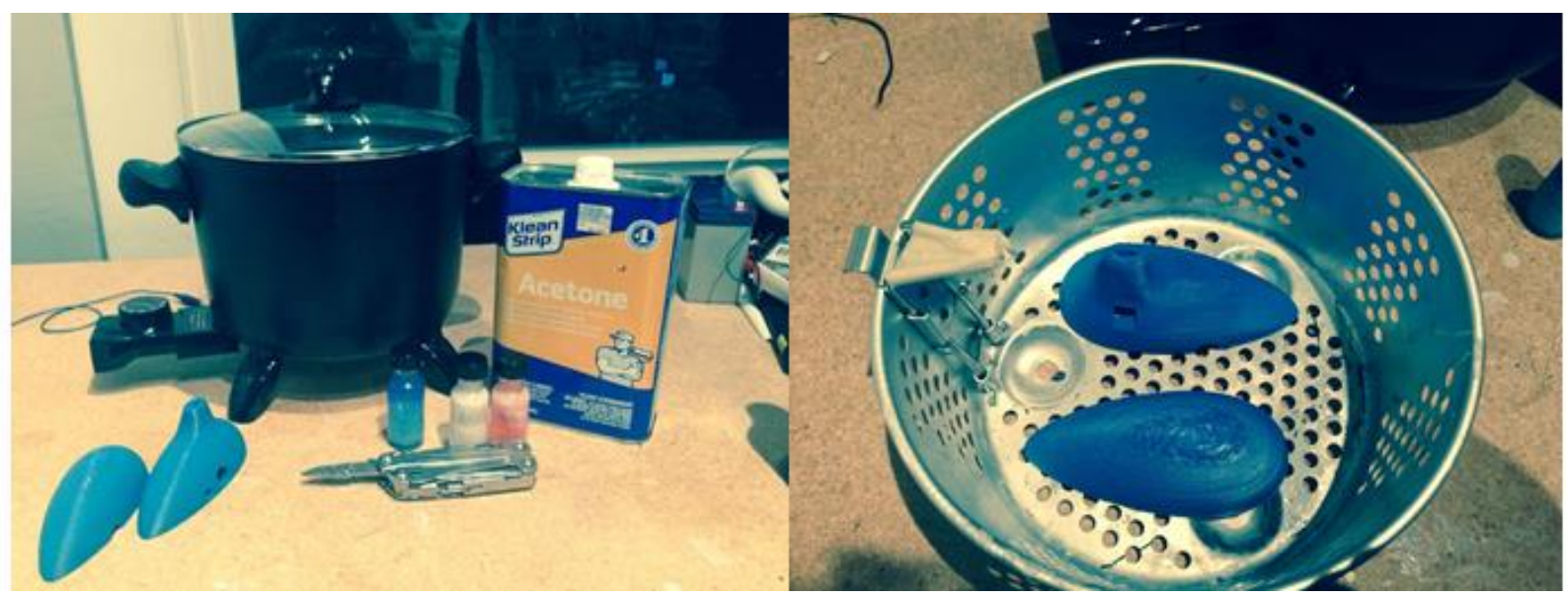

Figura 8 - Exemplo de arranjo com uso de uma panela elétrica. Fonte: http://www.instructables.com/id/Quality-Finish-3D-

\section{Prints-with-Acetone/.}

No arranjo da Figura 8 utiliza-se uma panela elétrica como câmara de tratamento e gerador de vapor de acetona. A peça é mantida separada da acetona líquida através do recipiente com furos aonde se dá a exposição da peça de vapor.

Este é um arranjo simples e efetivo, relativamente hermético no tocante ao vazamento de vapor de acetona, com controle de temperatura e logo da taxa de evaporação de acetona. Uma desvantagem é a exposição não homogênea da peça devido ao contato com o recipiente metálico, mas que poderia ser facilmente resolvido com a suspensão da peça.

Em um arranjo mais simples, mostrado na Figura 9, usa-se a fervura da água para controlar a temperatura em um recipiente com acetona no qual é suspensa uma peça. 


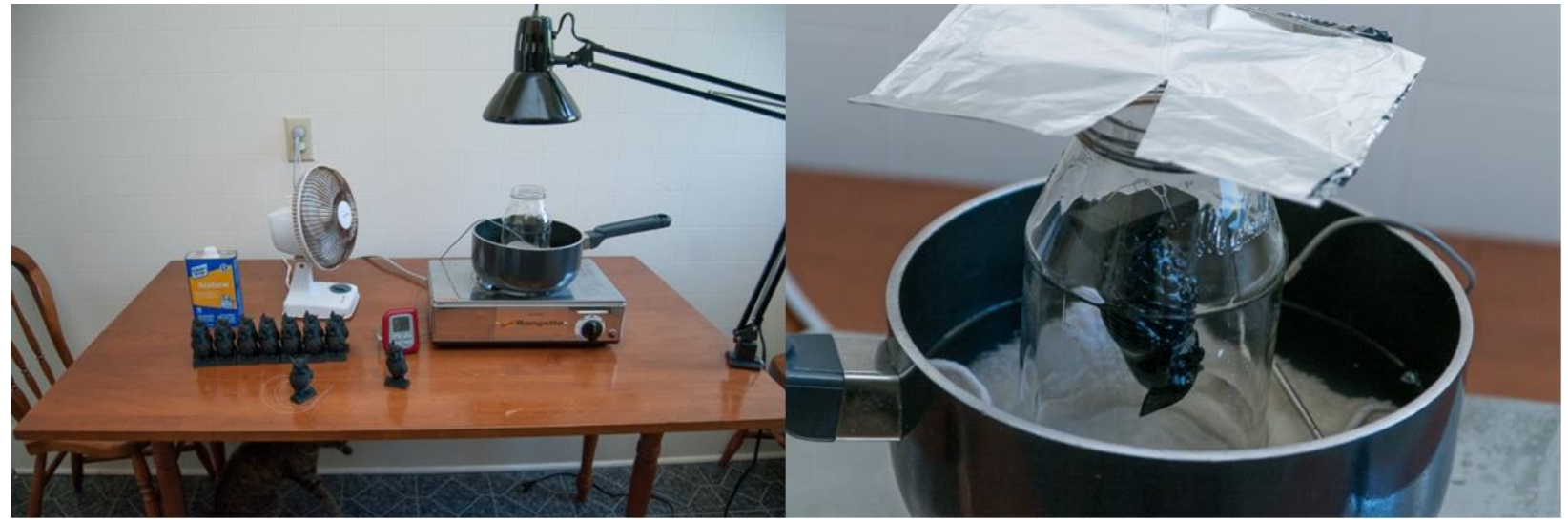

Figura 9 - Exemplo de tratamento utilizando uma mesa aquecida e água em ebulição para controle da temperatura. Fonte:http://sinkhacks.com/building-acetone-vapor-bath-smoothing-3d-printed-parts/.

Este método alegadamente produz resultados rapidamente e variações do aparato utilizado são inúmeras na comunidade de entusiastas. Por vezes a própria impressora 3D possui uma mesa aquecida com temperatura controlada, como na Figura 10.

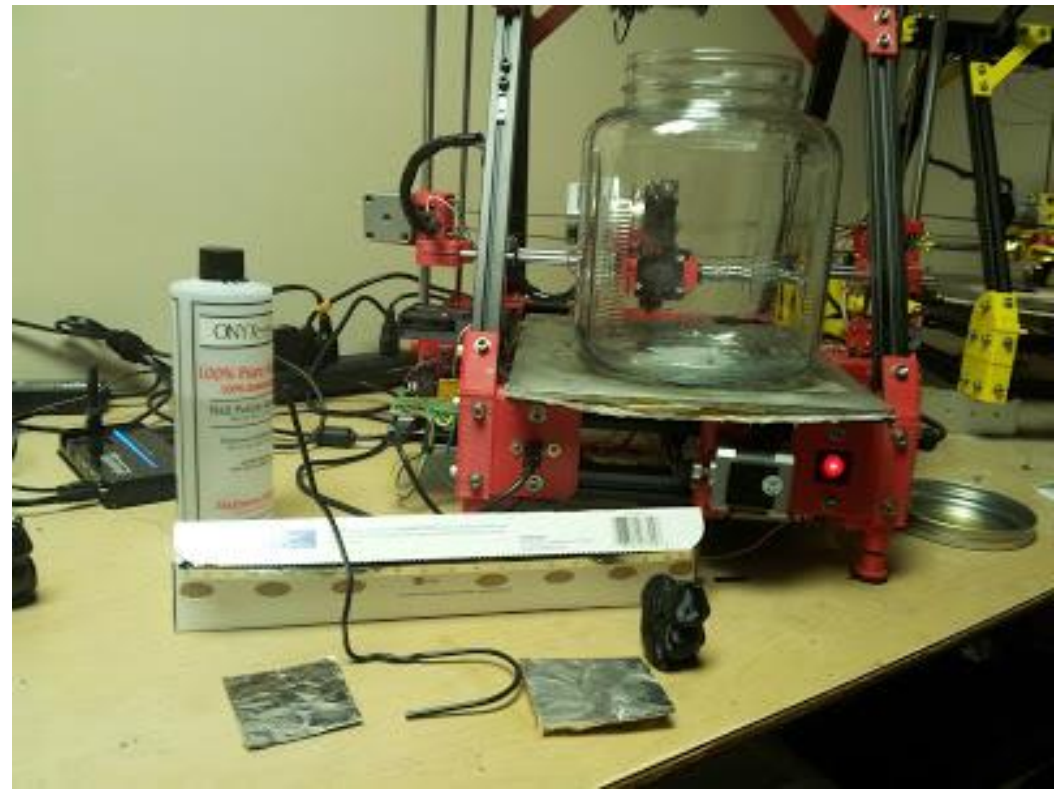

Figura 10- Exemplo de aparato que utiliza a mesa aquecida de uma impressora 3D open Source. Fonte: http://blog.reprap.org/2013/02/vapor-treating-abs-rp-parts.html.

Variantes mais complexas desse método também podem ser encontradas, e tentam se aproximar das soluções comerciais mostradas anteriormente, como mostrado na Figura 11. 


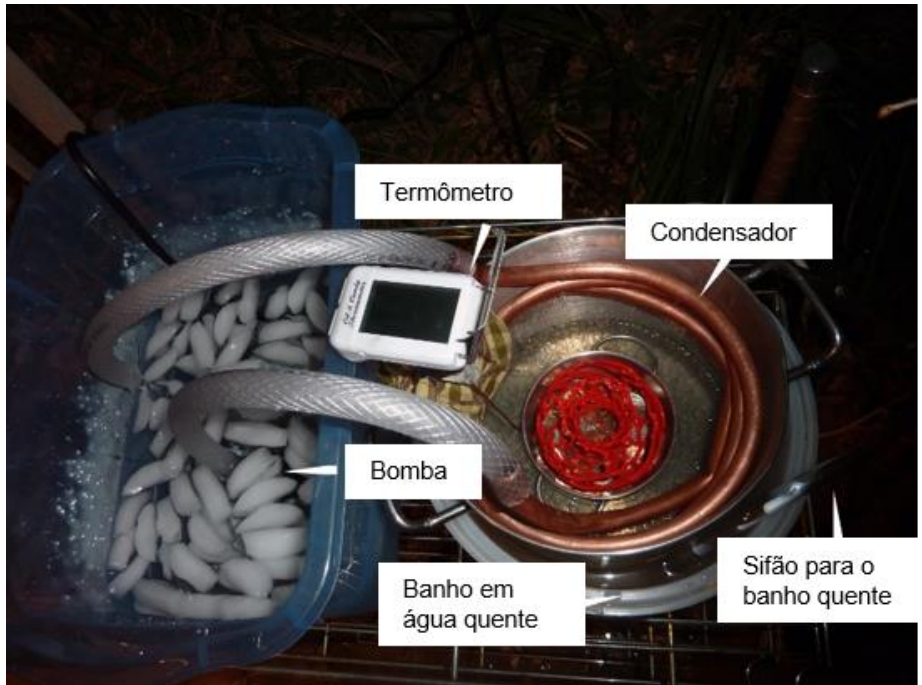

Figura 11 - Sistema de tratamento com recuperação do vapor de acetona. Traduzido de: http://www.soliforum.com/topic/183/diy-smoothing-station/.

Neste caso, ainda se expõe a peça ao vapor de acetona aquecido por água em ebulição, mas se adiciona uma serpentina resfriada para que o vapor que não entrou em contato com a peça se condense e volte para o fundo do recipiente aquecido.

Métodos nos quais se utiliza a acetona na fase líquida também podem ser encontrados, além do método mencionado no campo de estudos acadêmico. Tem-se como exemplo o seguinte aparato da Figura 12, no qual a peça a ser tratada é imersa em um tanque de acetona e posta a girar.

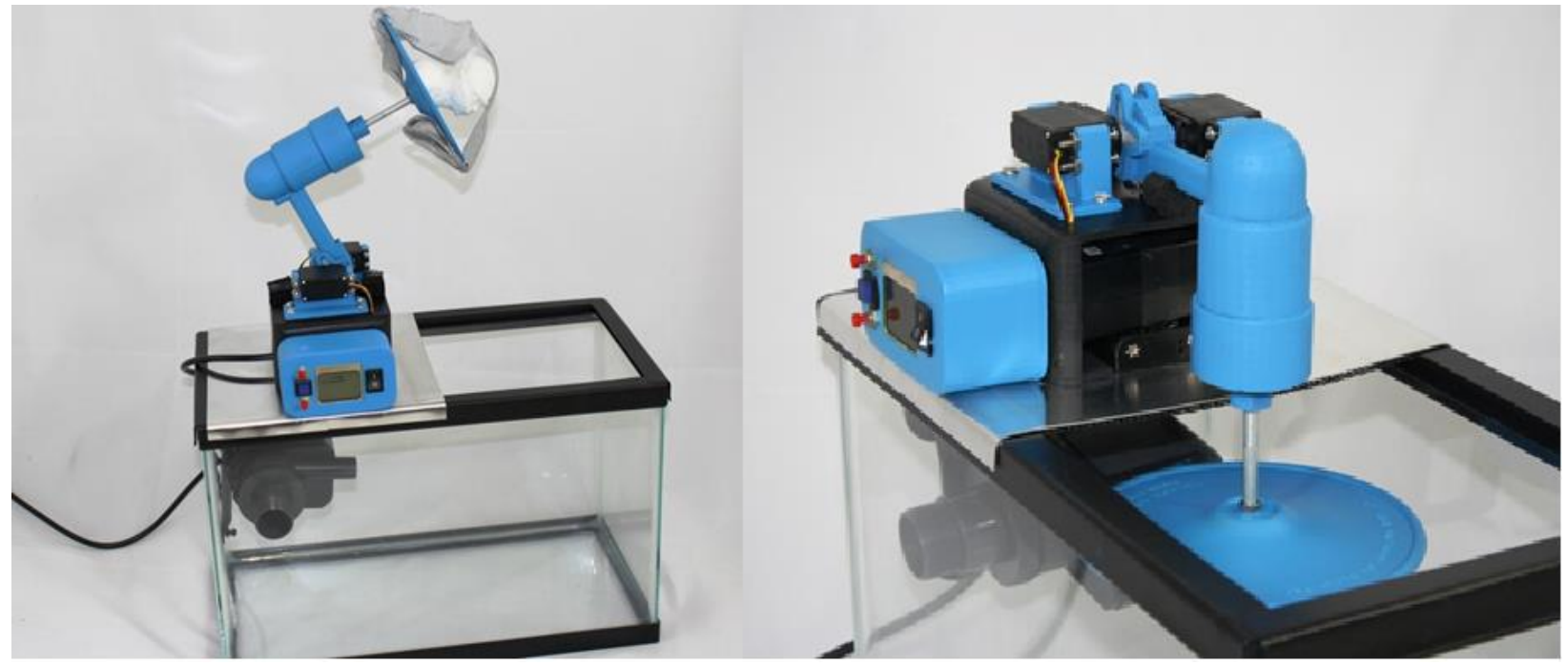

Figura 12- Exemplo de sistema de pós-tratamento com imersão em acetona líquida proposto em plataforma de financiamento coletivo. Fonte: https://www.kickstarter.com/projects/1809448130/3d-refiner-by-3dprintsexpresscom/description.

Neste caso, os projetistas alegam um tempo menor de tratamento e uma exposição mais homogênea da peça. Uma análise superficial constata que tal afirmativa é totalmente dependente do formato da peça e do eixo de rotação da mesma. Peças axissimétricas muito provavelmente se beneficiam do método enquanto peças mais oblíquas sofrem com o arredondamento das arestas.

Um método ainda mais simples é proposto, onde simplesmente se expõe a peça a uma atmosfera saturada de vapor de acetona a temperatura ambiente, mostrada passo a passo na Figura 13.

Para isto, um recipiente hermético com um volume de acetona em seu interior - no caso aqui mostrado, em toalhas de papel embebidas em acetona -é fechado com peça a ser tratada em seu interior. Após um certo tempo, remove-se a peça do recipiente e aguarda-se a cura da mesma. 


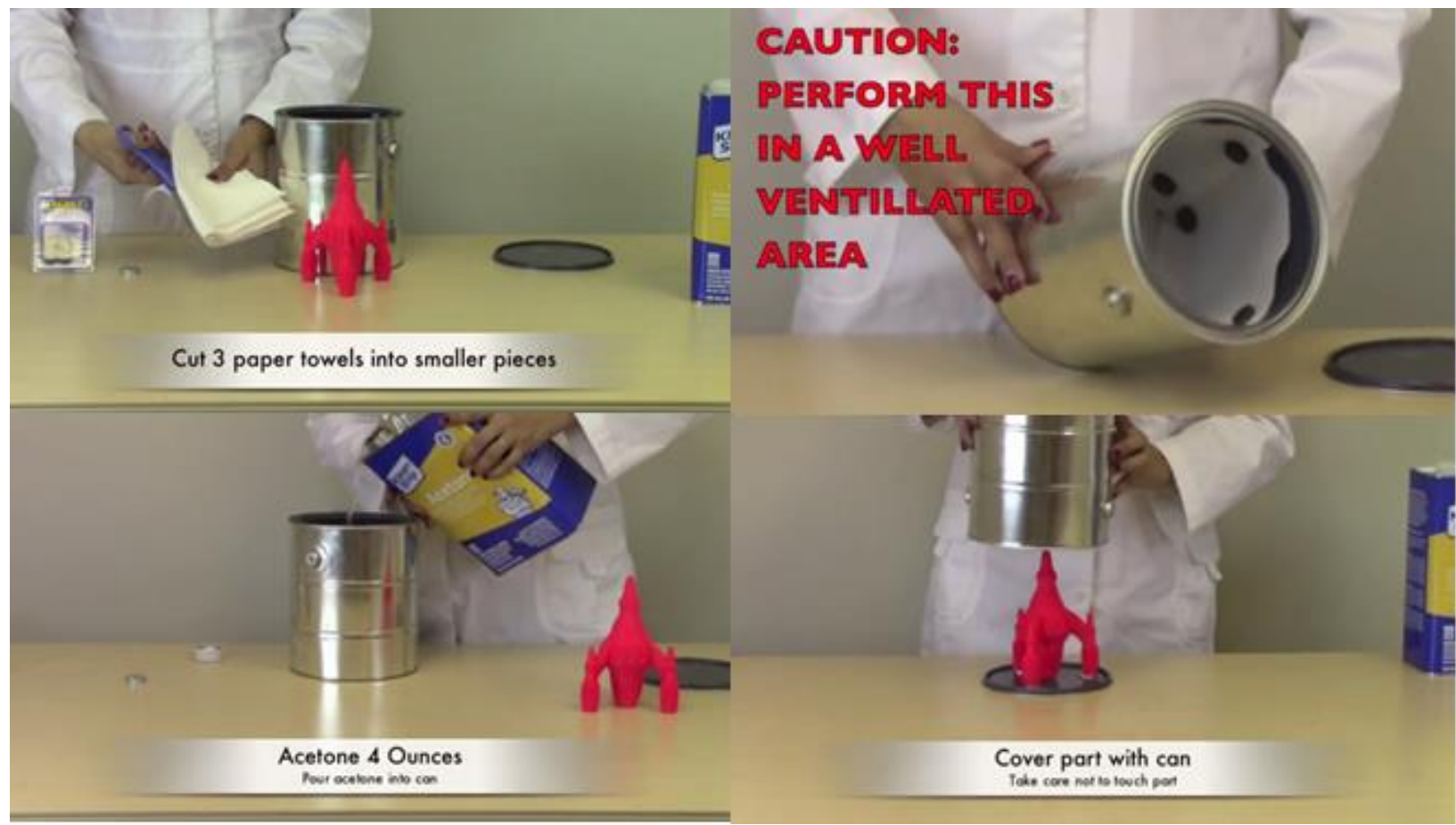

Figura 13 - Método de tratamento com vapor de acetona gerado em temperatura ambiente. Fonte: http://airwolf3d.com/2013/11/26/7-steps-shiny-finish-on-abs-parts-acetone/.

Este método, além de simples, tem potencial de produzir resultados bem controlados devido à menor taxa de dissolução das faces da peça, relacionada a menor concentração de acetona no ambiente devido a temperatura e pressão de vapor mais baixas.

A segurança para o operador neste método é significativamente maior já que não há aquecimento da peça ou uso de eletricidade a chance de incêndios acidentais é reduzida. O uso de um recipiente selado também reduz a exposição do operador ao vapor da acetona.

A crítica realizada é de que este método requer mais tempo de exposição da peça para um resultado similar aos métodos anteriores, o que pode ser esperado.

O contraponto a esta crítica é que comparado ao tempo de fabricação da peça, o tempo dispendido no pós-tratamento da mesma não chega a ser significativo.

Na seção seguinte, a luz da problemática e dos exemplos expostos aqui, se definem os objetivos que irão guiar o desenvolvimento deste trabalho. 


\subsection{OBJETIVOS}

Deseja-se parametrizar o funcionamento de alguns dos possíveis métodos de tratamento superficial de peças fabricadas em ABS com o uso de solventes.

O principal objetivo deste trabalho é definir parâmetros quantitativos para avaliar métodos de uso de solventes no tratamento superficial de peças fabricadas em ABS que produzam resultados que atendam aos seguintes objetivos:

- Produção de resultados previsíveis e replicáveis, avaliados através de parâmetros e critérios bem definidos;

- Capacidade de controle da rugosidade da peça a fim de se permitir a obtenção de similaridade geométrica na fabricação de modelos em escala reduzida para uso em experimentos de diferentes naturezas;

- Rugosidade mínima obtida suficiente para aplicações que demandam superfícies polidas, e.g. masters para moldes de fundição e injeção, próteses bio-compatíveis, peças de uso médico, entre outros;

É desejável também que a técnica desenvolvida atenda aos seguintes requisitos, de forma a facilitar a adoção da tecnologia nos diversos ambientes de uso, sejam eles dentro da academia, no setor privado e entre entusiastas.

- Baixa complexidade e custo do equipamento necessário;

- Baixa complexidade de operação;

- Baixo consumo de solvente;

- Alto grau de segurança para o usuário, mitigando riscos de incêndios e explosões e de exposição ao solventes e seus vapores; 


\subsection{ORGANIZAÇÃO DESTE TRABALHO}

Primeiramente, neste capítulo 1 se expôs o escopo e os objetivos do projeto, contextualizando o leitor dentro do universo de possibilidades do tema.

Segue-se no capítulo 2 para uma revisão dos temas tratados e correlatos aonde se explana brevemente o histórico e o funcionamento das técnica de manufatura aditiva abordada.

Tem-se como objetivo com a revisão levar o leitor até o contexto atual dos usuários e da origem dos problemas de qualidade das peças, para então propor o método de pós-tratamento químico com suas possíveis vantagens e benefícios.

A revisão bibliográfica também prepara o leitor para entender a seção seguinte, voltada a explanação da metodologia utilizada para atacar o problema proposto. Esta seção não mostra resultados obtidos e sim o arcabouço lógico utilizado para construir os experimentos e analisar os resultados obtidos.

O capítulo 3 - Metodologia - é voltado para o planejamento dos experimentos. Com o problema em mãos, expõe-se os passos e decisões a serem tomados para que os experimentos e validações possam ser realizados em uma ordem lógica, que entregue rapidamente rodadas de experimentos que permitam uma análise dos resultados para melhor execução da próxima etapa.

Na sequência apresentam-se os experimentos e resultados encontrados no capítulo 4.

Finalmente, na conclusão apresentada no capítulo 5, faz-se uma análise do trabalho como um todo, propondo recomendações de uso e estudos futuros no assunto. 


\section{REVISÃO DO ESTADO DA ARTE}

As principal referências para este trabalho foram os trabalhos realizados pelo grupo formado pelos pesquisadores Gianluca Percoco, Fulvio Lavecchia e Luigi Maria Galantucci (7) (8) (6) (9), todos do departamento de engenharia mecânica do Politécnico de Bari, na Itália.

O trabalho do grupo que serviu como base para este, intitulado Experimental study aiming to enhance the surface finish of fused deposition modeled parts (6) traz uma discussão sobre a qualidade da superfície das peças fabricadas via FDM e dos métodos disponíveis para o controle e a melhoria de tal.

Dando sequência ao primeiro trabalho, os pesquisadores propõem e realizam uma série de experimentos explorando o pós-tratamento das peças com imersão em solução aquosa de acetona, nos quais podem ser observados a redução da rugosidade superficial da peça, que foi medida antes e após os experimentos.

A discussão sobre a melhoria da qualidade superficial das peças levantada pelos pesquisadores mencionados existe em peso dentro da comunidade científica e pode ser dividida em dois grandes grupos de estratégias:

1- Otimização das técnicas e parâmetros de fabricação; da orientação da peça ao ser fabricada; dos algoritmos, softwares e lógicas utilizados durante o projeto da peça, preparo do modelo e das instruções de máquina utilizadas;

2- Investigação de técnicas de pós-tratamento;

Pode-se dizer que o primeiro grupo aborda todas as estratégias que podem ser utilizadas antes da fabricação da peça para garantir que a mesma seja fabricada da melhor forma possível.

No segundo grupo, trabalha-se com o seguinte cenário: dado que a peça já está fabricada, quais técnicas podem ser aplicadas para que a partir daqui obtenhamos a melhor superfície possível para a aplicação.

Como exemplo dos esforços inclusos na primeira categoria, podemos citar os trabalhos das referências (10), (11), (12), (13), (14), (15) e (5) onde são abordadas diversas técnicas focadas em todos os passos antes da peça estar fabricada: otimização do modelo da peça; seleção da melhor orientação para fabricação da peça; otimização da estratégia de slicing - o fatiamento do modelo para fabricação em camadas e a otimização dos parâmetros de máquina utilizados na fabricação.

Como dito anteriormente, o objetivo do trabalho é parametrizar pelo menos um método de uso de solventes no tratamento superficial de peças fabricadas em ABS que produza resultados que atendam aos critérios previamente estabelecidos, e enquanto relevantes para a área de fabricação aditiva como um todo, os trabalhos que foram discutidos no parágrafo anterior não são de relevância para o escopo.

Dentro da investigação que vem sendo realizada nas técnicas de pós-tratamento dos artefatos fabricados por manufatura aditiva, podemos iniciar a revisão pelo trabalho bem compreensivo de Kumbhar e Mulay (16) onde são comparados diversos métodos de manufatura aditiva, com as respectivas rugosidades atingidas e também de técnicas de pós-tratamento utilizadas, que no trabalho em revisão se dividem em técnicas convencionais e não convencionais, como mostrado na Tabela 1- Métodos de Pós-Tratamento, retirado e traduzido de (9). 
Tabela 1- Métodos de Pós-Tratamento, retirado e traduzido de (9)

\begin{tabular}{|c|c|}
\hline \multicolumn{2}{|c|}{ Métodos de pós-tratamento } \\
\hline Convencionais & Não-Convencionais \\
\hline $\begin{array}{l}\text { a. Abrasão em bacia vibratória; Jato } \\
\text { abrasivo }\end{array}$ & a. Abrasão ultrasônica \\
\hline b. Lixamento vibratório & b. Tratamentos químicos \\
\hline $\begin{array}{l}\text { c. HCM - Usinagem por corte a } \\
\text { quente }\end{array}$ & c. Polimento Eletroquímico \\
\hline d. Polimento óptico (à mão) & d. Galvanoplastia \\
\hline e. Usinagem CNC & e. Laser MMP \\
\hline $\begin{array}{l}\text { f. Processos de micro usinagem - } \\
\text { MMP }\end{array}$ & \\
\hline $\begin{array}{l}\text { g. Preenchimento dos sulcos com } \\
\text { uso de resina epóxi; Emassamento } \\
\text { e pintura }\end{array}$ & \\
\hline
\end{tabular}

Dentre as técnicas citadas encontramos tanto processos que requerem ferramental simples - associados a trabalhos manuais que requerem um grau de habilidade de quem aplicará a técnica, o que geralmente implica baixa repetibilidade e controle - quanto processos complexos, que requerem maquinário especializado e de custo geralmente incompatível com as impressoras 3D que estão sendo popularizadas.

Diversos estudos podem ser encontrados citando aplicações das técnicas mencionadas na tabela anterior, como nos trabalhos de Pulak et al (17), Fischer e Schöppner (18), Williams e Melton (19) e também dos próprios autores do estudo que motivou este trabalho (7).

Nesses trabalhos, analisam-se os resultados da aplicação primariamente de métodos convencionais, aonde se encontram resultados positivos, de alta repetibilidade e comprovados, mas que por outro lado demandam técnicas e equipamentos dificilmente acessíveis ao público beneficiado com a popularização das impressoras 3D.

Ainda que distantes do objetivo da investigação corrente, os métodos utilizados por estes autores estão perfeitamente adequados para aplicações de alto custo e complexidade no qual se utilizam impressoras e técnicas diferenciadas na fabricação dos artefatos.

Kuo e Su (20) analisam um método ainda classificado como convencional na tabela anterior, mas simples quando comparado aos estudos nos parágrafos anteriores.

No trabalho se analisa o uso de uma camada de epóxi - filler - a ser depositada sobre a peça fabricada em ABS a fim de preencher os espaços entre as camadas da impressão. No estudo em questão a camada de epóxi é aplicada com uma ferramenta desenvolvida pelos pesquisadores.

Mesmo simplificado, o método proposto por Kuo e Su ainda se distancia do objetivo do trabalho devido a necessidade de uma ferramenta de aplicação do filler para cada peça fabricada. Existem produtos disponíveis no mercado que são denominados fillers auto niveladores, que diminuem a necessidade de ferramentas específicas, mas que ainda demandam acabamento final por parte do usuário.

Dentro do contexto das técnicas de pós-tratamento não-convencionais e agora com atenção aos tratamentos químicos das peças fabricadas, encontramos além dos estudos realizados pelo grupo de Percoco, Lavecchia e Luigi Galantucci, um trabalho investigando a modificação de peças fabricadas em ABS para a obtenção de uma superfície a prova d'água (21).

No estudo de McCullough e Yadavalli (21), peças de ABS são imersas em acetona para a obtenção de vedação contra água em superfícies externas e em canais internos. No estudo se varia a concentração da solução da acetona e o tempo de imersão para se obter resultados diferentes e também para avaliar a preservação das características mecânicas e dimensionais das peças fabricadas devido a dissolução da mesma.

Os pesquisadores obtiveram sucesso na vedação das peças, apesar das dificuldades iniciais no controle do grau de dissolução da peça. 
Retornando aos trabalhos do grupo da Politécnica de Bari, após o trabalho inicial do grupo (6) - no qual foi evidenciada a redução da rugosidade superficial de corpos de prova quando imersos em uma solução aquosa de acetona - o grupo realizou mais uma série de experimentos a fim de se investigar mudanças no comportamento mecânico das amostras tratadas, através de testes de resistência à tração, flexão e compressão, que para vários dos casos estudados, mostraram melhorias (8), (9).

Em concordância com a motivação desta tese de mestrado, a literatura reforça a busca na melhoria da qualidade das peças fabricadas via processos de manufatura aditiva, inclusive por FDM e os resultados mostram aplicabilidade em diversas frentes: redução controlada da rugosidade, impermeabilização de superfícies e melhoria das propriedades mecânicas dos artefatos.

Faz parte também da preocupação dos grupos de estudo, a simplificação do método de tratamento das peças, como elucidado tanto pelo grupo Italiano assim como pelos pesquisadores Kuo e $\mathrm{Su}$.

Para os fins do presente trabalho, ressalta-se que dentre todos os estudos realizados, não houve consenso em relação ao corpo de prova utilizado para a realização dos experimentos, e o estudo de Moylan et al. (22) traz à tona uma discussão em voga - tanto na comunidade científica assim como na de hobbystas, comercial e industrial - sobre a padronização de artefatos de teste para se avaliar a qualidade de impressões 3D. Seja para fins de comparação de máquinas diferentes, tratamentos superficiais ou até mesmo estratégias de otimização de impressão.

Portanto, neste trabalho se adotará um corpo de prova que apresente as características necessárias para a avaliação do cumprimento dos objetivos do trabalho. 


\section{METODOLOGIA}

Nesta seção será apresentada a metodologia utilizada para a abordagem da investigação proposta.

Na Figura 14 estão os passos propostos para se chegar em uma especificação de uso de um método de pós-tratamento químico de uma peça.

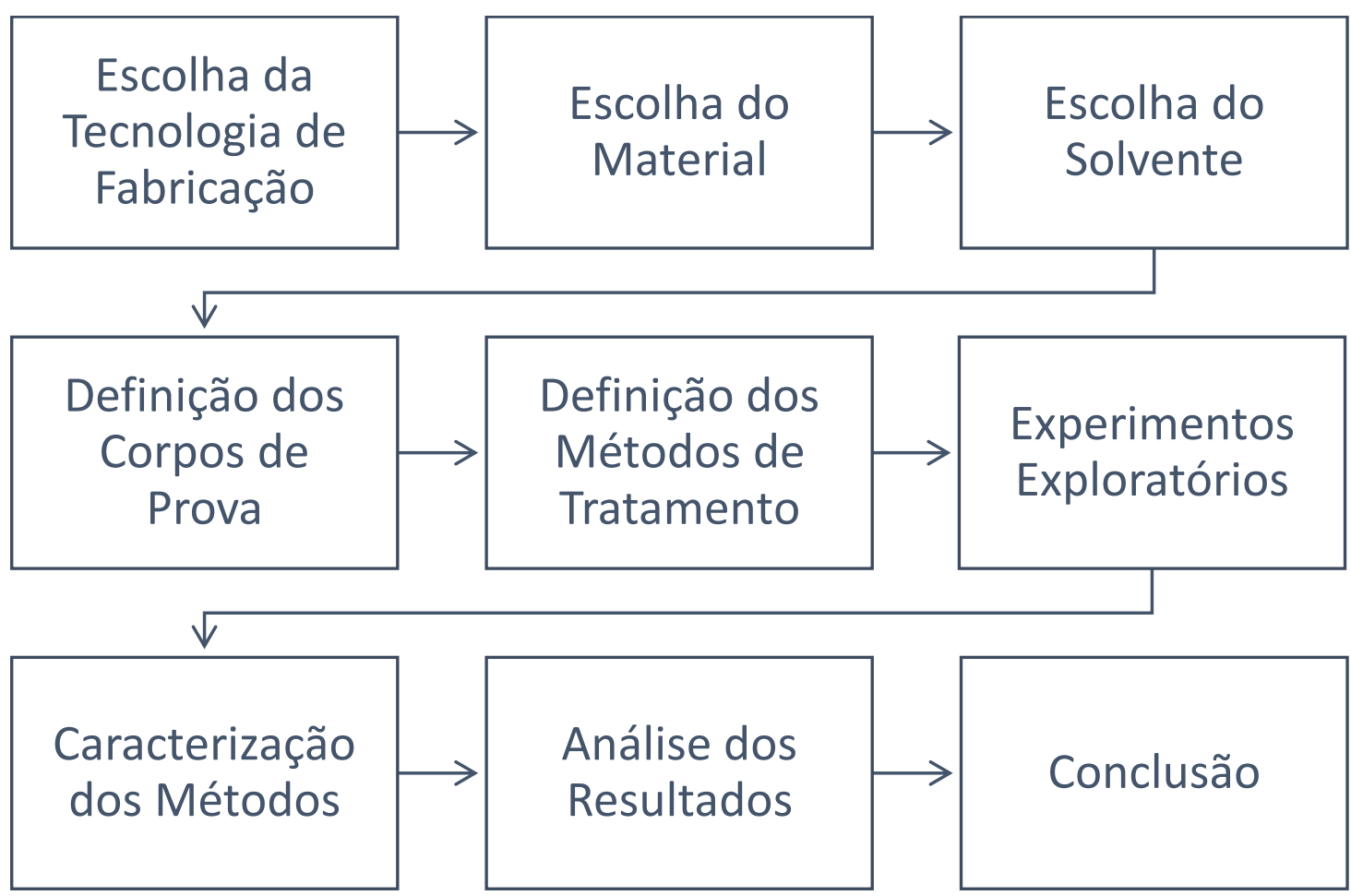

Figura 14- Fluxograma da investigação proposta.

Iniciando pelo primeiro passo, a tecnologia de fabricação sendo abordada é a de FDM - Fused Deposition Modelling, também chamada de FFF - Fused Filament Fabrication, pela recente popularização da mesma e pelo interesse da melhoria contínua dos resultados obtidos, como mostrado nas seções anteriores.

Na sequência, define-se como material utilizado nas peças o ABS, que foi escolhido dentre as opções disponíveis para a tecnologia de fabricação devido ao seu uso altamente difundido, disponibilidade, características de solubilidade e propriedades mecânicas entre outros já mencionados previamente.

Nas seções subsequentes, aborda-se os outros passos que compõem a metodologia proposta. 


\subsection{ESCOLHA DO SOLVENTE A SER UTILIZADO}

O material escolhido, ABS, é um polímero com um baixo grau de reticulação de sua estrutura, incluindo uma função nitrílica que interage de forma fraca com solventes polares, como ésteres, cetonas e cloretos (6).

Dentre as opções disponíveis no mercado que de solventes para o ABS, temos:

- Dimetilcetona, conhecida como Acetona;

- Ciclohexanona, um solvente industrial;

- 1,2 - Dicloroetano, um intermediário na produção do PVC;

- Metil-etil-cetona, conhecida também como MEK ou Butanona, um solvente industrial;

Dentre as características que definem um bom solvente para esta aplicação estão:

- Baixa ou nenhuma toxicidade;

- Segurança no uso, no sentido de e interessante que a substancia seja estável a combustão, explosões ou outras reações químicas;

- Fácil disponibilidade;

- Custo acessível;

- Alta efetividade no tratamento das peças;

Optou-se pelo uso da Dimetilcetona por uma série de fatores, listados na sequência:

- Disponibilidade e custo. Mesmo a venda sendo controlada e limitada para a Acetona pura, o volume mensal permitido para compra é mais do que o suficiente para a maior parte das aplicações. A depender da finalidade, pode-se encontrar facilmente em farmácias em forma de solução;

- Quesitos de segurança como flamabilidade e grau de toxicidade mais baixos ou tão bons quanto os outros solventes citados;

- Alta solubilidade em água, em uma razão de aproximadamente 1:1 em volume. Isso permite, se necessário, um grande controle da concentração da solução utilizada para o tratamento, como mencionado em (21);

- Uso em estudos prévios. No trabalho citado anteriormente (6), a Acetona havia sido utilizada em uma solução aquosa de $90 \%$ em volume para a redução da rugosidade superficial de peças fabricadas em ABS. Realizar um experimento similar para fins de benchmark é bastante relevante para o trabalho. 


\subsection{CORPOS DE PROVA}

Para que se possa analisar os resultados procurados de forma objetiva, faz-se necessário o uso de um corpo de prova $(\mathrm{CP})$ padrão para a realização dos testes.

Este CP deve ser representativo das dificuldades do processo de fabricação e que mostre de forma clara como as limitações do método de fabricação podem ser corrigidas com o pós-tratamento.

Como mencionado anteriormente, problemas de qualidade relacionados a overhangs e a necessidade de suporte podem ser atacados com uso de filamentos adequados para suportes solúveis e também com técnicas de resfriamento do filamento extrudado e melhorias em software.

O problema de acabamento mais crítico atualmente está relacionado ao efeito staircase e é intrínseco ao método de fabricação. Este pode ser amenizado com a redução da espessura de camada da impressão ou com otimizações na escolha da orientação da peça, como citado anteriormente.

Então, para melhor analisar as capacidades dos métodos propostos, deve-se tratar uma superfície aonde o efeito staircase seja facilmente visível.

Dessa forma então decidiu-se utilizar um sólido com uma face inclinada como CP. Esta inclinação deve ser tal que o uso de material de suporte não seja necessário para a fabricação e que o efeito staircase fique claramente visível, para posterior medição de sua rugosidade.

Como não existe um consenso entre a comunidade cientifica para este tipo de corpo de prova (22), é proposto o modelo da Figura 15.

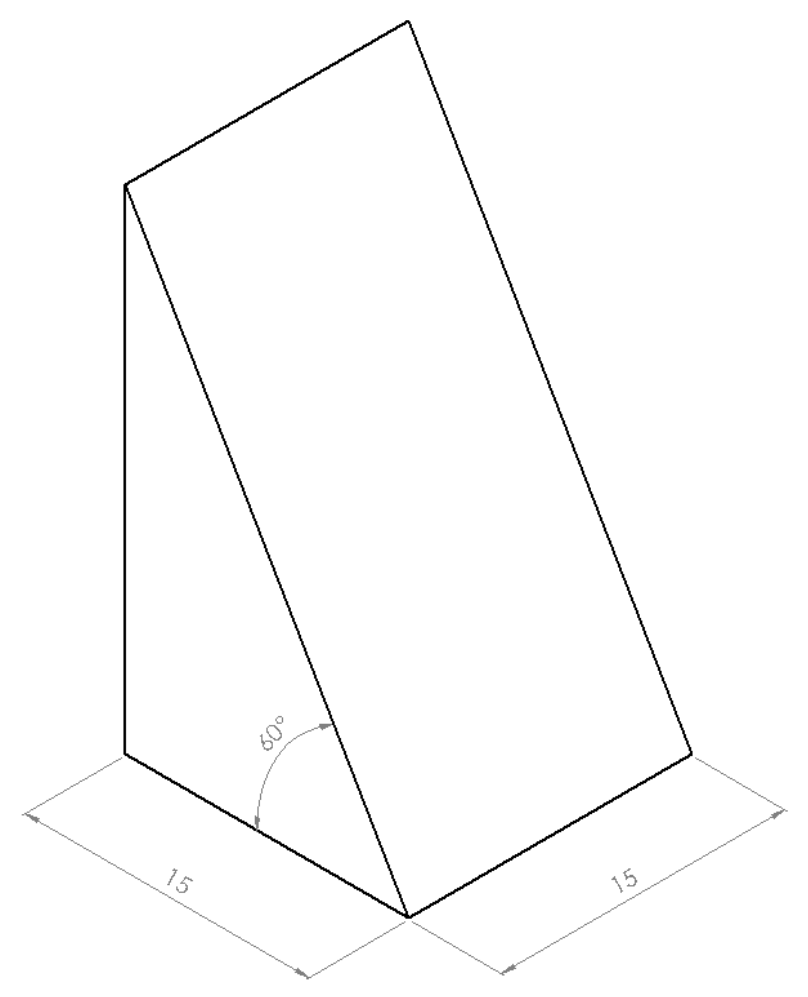

Figura 15- Modelo do CP proposto, com as dimensões retratadas em $\mathrm{mm}$.

As dimensões foram escolhidas de forma a se facilitar a fabricação em lotes do CP, economizar material e reduzir a quantidade de solvente necessária para se tratar todas as amostras. 


\subsubsection{FABRICAÇÃO DOS CORPOS DE PROVA}

Os corpos de prova foram fabricados utilizando uma impressora 3D comercial, modelo Replicator $2 X$ comercializado pela fabricante Makerbot, que é adequada para a impressão com filamentos de ABS.

Em relação às especificações técnicas da máquina (23), são relevantes para este trabalho os dados de espessura de camada, neste caso limitadas inferiormente a $0,1 \mathrm{~mm}$ e a precisão de posicionamento de $0,011 \mathrm{~mm}$ nas direções do plano de trabalho e de $0,0025 \mathrm{~mm}$, que indicam qual a ordem de grandeza da precisão máxima a ser obtida na fabricação dos corpos de prova.

$\mathrm{O}$ material utilizado para a fabricação foi o ABS, fornecido em rolos de filamento com $1,75 \mathrm{~mm}$ de espessura. Mais especificamente foi utilizado um carretel fornecido pela fabricante Matterhackers da linha ABS PRO Series, na cor preta.

Para gerar os arquivos de impressão, foi utilizado o software Simplify $3 D$ que permite grande controle dos parâmetros de fabricação, visualização prévia do processo e possui uma engine de impressão otimizada em relação as opções de softwares abertos ou o fornecido junto ao equipamento.

A peça foi impressa nas configurações de alta qualidade, utilizando-se das configurações padrão da máquina a fim de emular um processo padrão de um usuário não especialista na tecnologia, que resulta em uma espessura de camada de $0,1 \mathrm{~mm}$, a fim de se minimizar o efeito staircase conforme mencionado nos capítulos anteriores.

Não foi foco deste trabalho otimizar os parâmetros de impressão a fim de se obter a mínima rugosidade superficial pré-tratamento. 


\subsection{MATERIAIS E MÉTODOS}

realizados.

Esta seção cobre os pontos envolvidos no planejamento e preparação dos experimentos que foram

São descritos os materiais, instrumentos, arranjos experimentais e métodos utilizados para a realização dos tratamentos nos corpos de prova.

\subsubsection{MATERIAIS E INSTRUMENTOS UTILIZADOS}

\section{- Solvente utilizado}

O solvente utilizado foi a Acetona Pura (C3H6O) fabricada pela Vetec Química Fina, com teor mínimo de 99\%, apresentada na Figura 16.

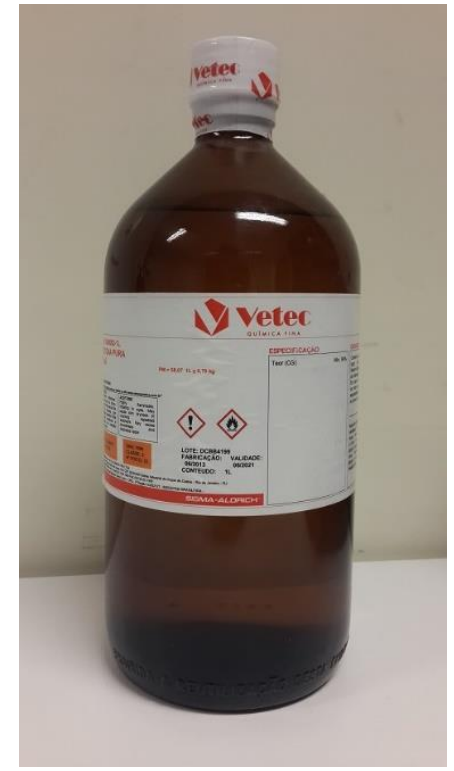

Figura 16- Acetona Pura. 


\section{- Mesa aquecida}

Foi utilizada uma mesa aquecida apresentada na Figura 17, marca GRM Products, com controle digital de temperatura para se obter as condições experimentais controladas necessárias.

O equipamento utilizado tem potência máxima de $280 \mathrm{~W}$ e atinge temperaturas de até $130^{\circ} \mathrm{C}$.

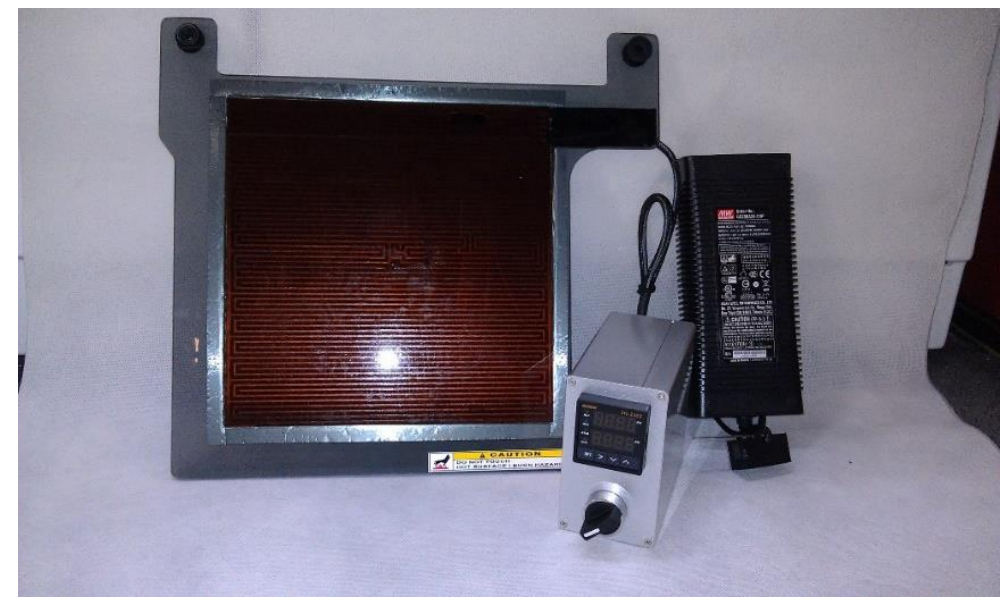

Figura 17 - Mesa aquecida marca GRM Products.

\section{- Rugosímetro}

O equipamento utilizado foi um rugosímetro de contato Mitutoyo SJ-201 (24) e que pode ser visto na Figura 18.

O equipamento possui uma resolução de $0,01 \mu \mathrm{m}$ e é capaz de realizar medições dos parâmetros comuns Ra, $\mathrm{Rq}$ e Rz, que respectivamente representam a média aritmética dos valores absolutos medidos, o valor RMS dos valores medidos e a média dos valores máximos e mínimos medidos. Além destes, o equipamento é capaz de realizar outras medidas, conforme descrito em seu datasheet.

Todo o preparo para as medições e a avaliação do erro experimental é descrito adiante.

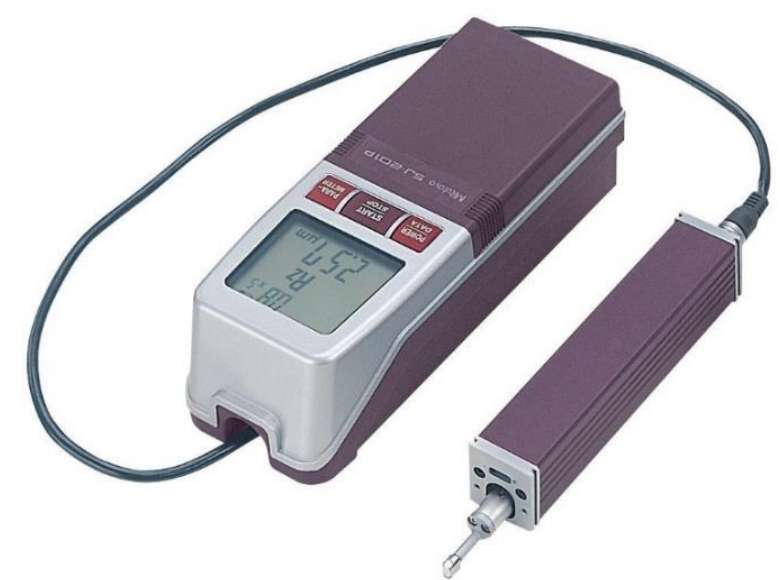

Figura 18- Rugosímetro Mitutoyo SJ-201. 


\subsubsection{MÉTODOS PROPOSTOS}

Os métodos aqui propostos são baseados tanto em trabalhos científicos realizados previamente (6) (21), tanto quanto em equipamentos comerciais e de exemplos de uso da comunidade de hobbystas.

Estes métodos foram selecionados baseados na capacidade de uso como benchmark de referência (6), simplicidade, bons resultados obtidos por terceiros e recorrência de uso dentro da comunidade de fabricação aditiva.

\section{- Imersão total da peça em uma solução de acetona;}

O teste de imersão da peça em uma solução de acetona, é um teste simples e que oferece um bom parâmetro de comparação, por já ter sido realizado por outro grupo de pesquisa (6).

As desvantagens do método incluem que grandes volumes de acetona são necessários tratamento de peças maiores e que a flutuabilidade da peça sendo tratada é algo que deve ser contornado, visto que o ponto pelo qual a peça é mantida submersa, quando do amolecimento do plástico, pode sofrer marcas permanentes.

Para este método, o aparato experimental utilizado é simplesmente um recipiente no qual foi depositado 100ml de solução aquosa de acetona a $90 \%$ em volume. A peça foi imersa forçadamente nessa solução - devido a flutuabilidade - pela face inferior do CP. A Figura 19 representa o aparato utilizado.

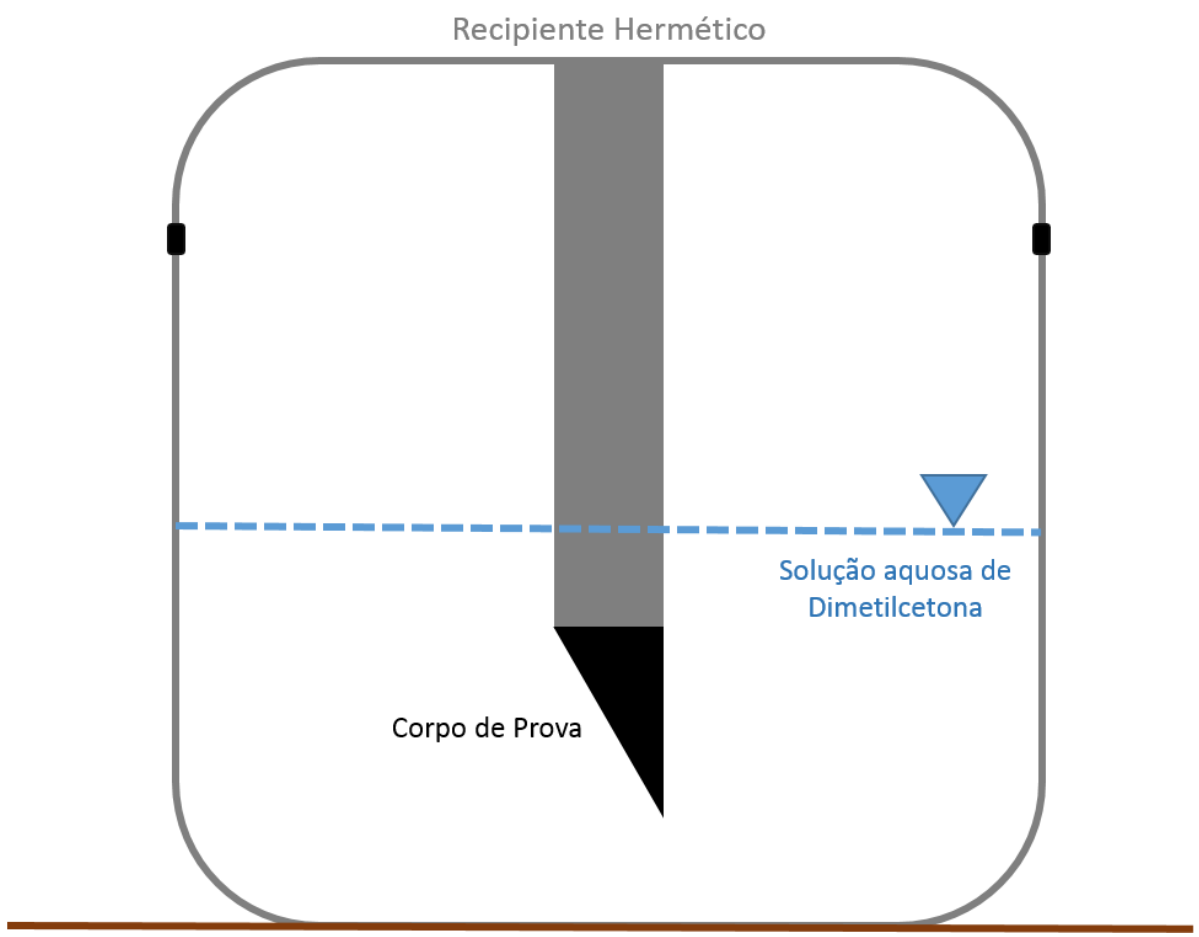

Figura 19- Representação do aparato experimental de imersão. 


\section{- Exposição da peça ao vapor de acetona em ebulição;}

Este método de exposição da peça a ser tratada ao vapor de acetona em ebulição foi testado por membros da comunidade de usuários das tecnologias de impressão 3D, como mencionado anteriormente, com resultados positivos na aparência final das peças. Variantes do método também são aplicados em sistemas comerciais.

Problemas de segurança do usuário não foram reportados até o momento da pesquisa realizada para este trabalho, como, por exemplo, casos de intoxicação ou combustão do vapor de solvente.

Este método tem possíveis vantagens devido ao pequeno volume de solvente comparado ao volume da peça e a capacidade de se controlar a taxa de geração de vapor através da potência da fonte de aquecimento.

Para este método o aparato experimental utilizado foi um recipiente de fundo metálico e de grande altura em relação ao diâmetro, para que pudesse se estabelecer uma corrente convectiva de vapor de acetona.

$\mathrm{O}$ recipiente foi posicionado sobre a mesa aquecida e um reservatório interno de acetona em contato com a mesa aquecida foi preenchido com um volume fixo de acetona $-30 \mathrm{ml}$ - a cada corrida experimental.

Para cada ensaio, esperava-se o início da ebulição da acetona, caracterizada pela formação de bolhas de vapor de acetona antes que o recipiente fosse fechado. Na sequência o $\mathrm{CP}$ era posicionado em um suporte próximo ao topo do recipiente, de forma a receber a corrente de vapor de acetona convectada naturalmente.

A Figura 20 representa o arranjo experimental.

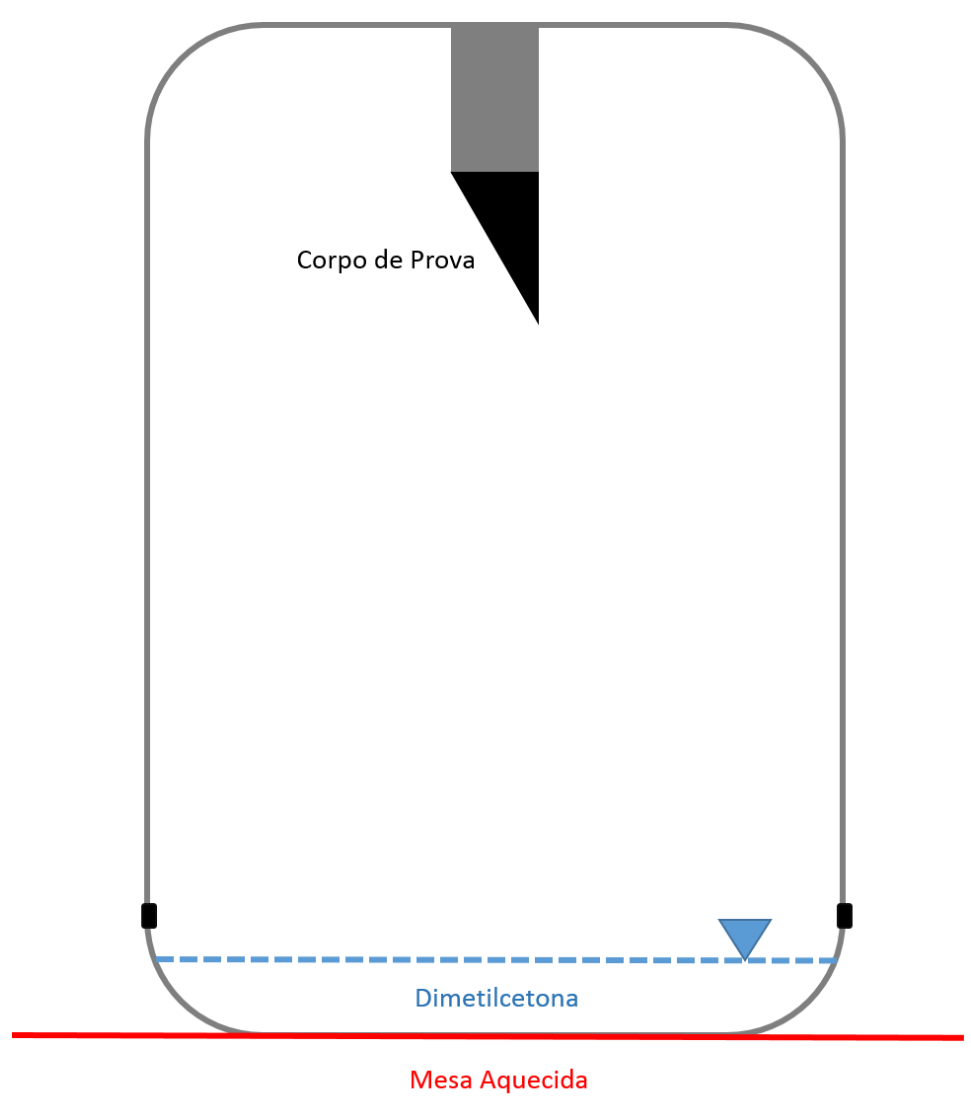

Figura 20 - Representação do aparato experimental de ebulição. 


\section{- Exposição da peça a uma atmosfera saturada de vapor de acetona a temperatura ambiente;}

Com exemplos de uso encontrados apenas na comunidade de usuários da tecnologia, esse método no qual se expõe a peça a uma atmosfera saturada de acetona em um recipiente hermético, é o mais simples de todos os propostos, tendo como possível desvantagem em relação aos outros o maior tempo de exposição necessário devido a menor concentração do solvente no ambiente de tratamento da peça.

Para o restante deste trabalho, esta método será referenciado como Pvap @ $21^{\circ} \mathrm{C}$.

Para este método foi utilizado um recipiente no qual foi depositado $20 \mathrm{ml}$ de acetona pura. O volume deste recipiente foi de aproximadamente 17 vezes o volume do $\mathrm{CP}$, a fim de se caracterizar que a concentração de vapor de acetona naquela atmosfera não varie em função da interação com a camada superficial do $\mathrm{CP}$, como no conceito de reservatório infinito.

O CP foi colocado dentro do recipiente em cima de um bloco de alumínio - que não reage com a acetona e tampouco com o ABS - a fim de se estabilizar a temperatura no ambiente de teste.

Para este experimento, a sala de testes foi mantida climatizada a $21{ }^{\circ} \mathrm{C}$ e aguardou-se até que a temperatura do aparato experimental entrasse em equilíbrio térmico. Para tal, um termômetro infravermelho foi utilizado para a verificação durante um intervalo de duas horas. Segue na Figura 21 a representação do arranjo experimental.

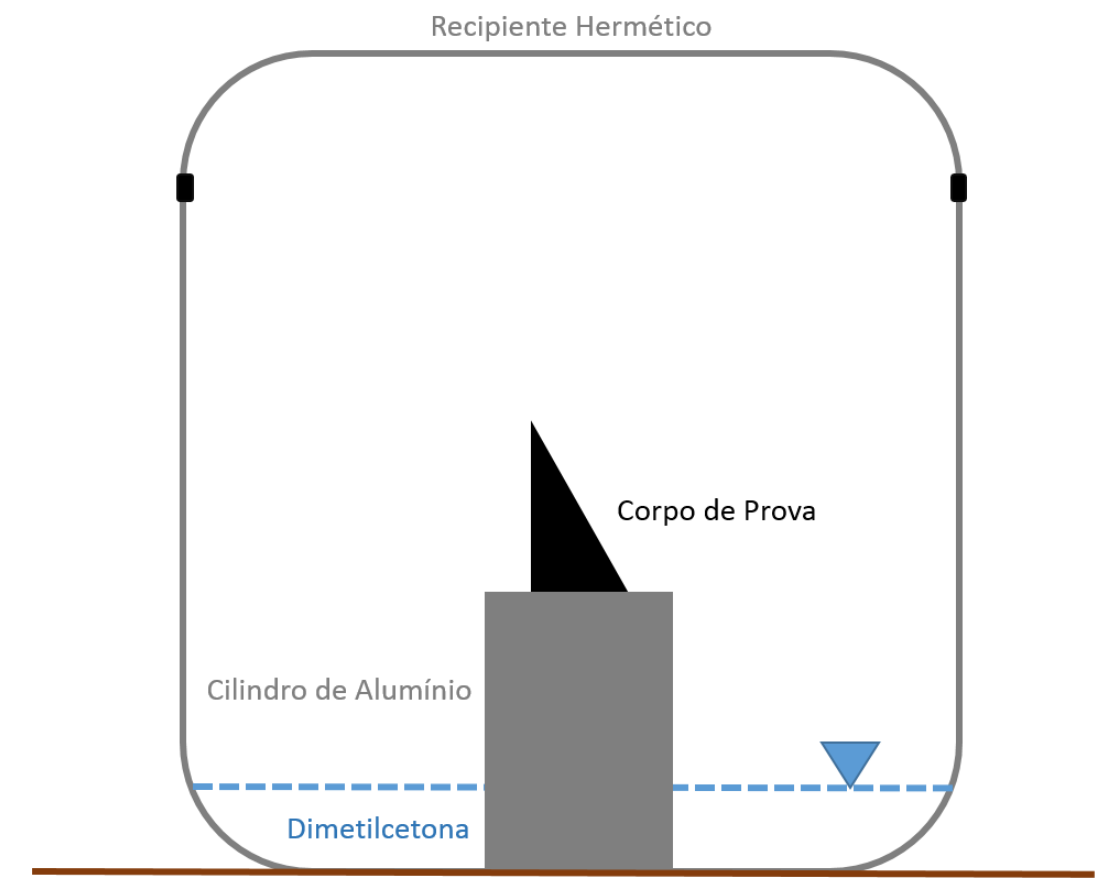

Figura 21 - Representação do aparato experimental de Pvap @ $21^{\circ} \mathrm{C}$. 


\section{- Exposição da peça a uma atmosfera saturada de vapor de acetona a temperatura de $50^{\circ} \mathrm{C}$.}

Aqui se segue a mesma lógica do experimento proposto anteriormente, mas verificando se o aumento na temperatura do experimento - e logo na pressão de vapor de acetona - produz resultados de forma mais rápida.

Utilizou-se o mesmo arranjo experimental do experimento anterior, mas com o uso da mesa aquecida para se modificar a temperatura do recipiente.

Foi adotada a hipótese de que a massa de alumínio representa praticamente toda a carga térmica do experimento, e que quando a mesma estivesse em temperatura estável, podia se considerar a temperatura da câmara como estável e próxima da temperatura medida.

Ajustou-se a temperatura da mesa para $60^{\circ}$ e verificou-se a temperatura interna do recipiente medindose com o termômetro infravermelho a temperatura na base da peça de alumínio que foi tomada como a temperatura da acetona no recipiente. As medições foram feitas em um intervalo de duas horas para se garantir a estabilização do gradiente temperatura do recipiente.

A temperatura de $60^{\circ} \mathrm{C}$ para a mesa foi obtida através de tentativa e erro, medindo-se a temperatura da peça de alumínio com o objetivo de se obter a temperatura de $50^{\circ} \mathrm{C}$ para o experimento. Na Figura 22 representa-se o aparato experimental.

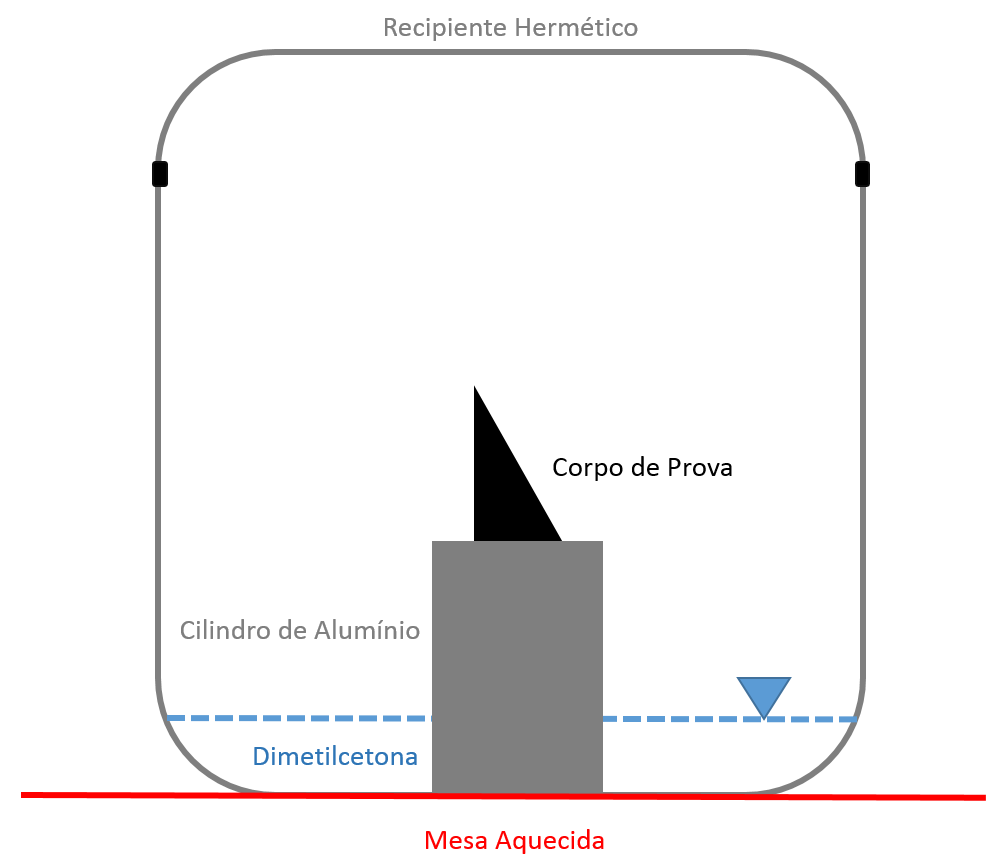

Figura 22- Representação do aparato experimental de Pvap @ 50 ${ }^{\circ} \mathrm{C}$. 


\subsection{EXPERIMENTOS EXPLORATÓRIOS}

Inicialmente conhecia-se pouco a respeito do funcionamento prático de cada método selecionado de forma que iniciar o trabalho com a caracterização dos mesmos - aqui entendida como a formação da relação da redução da rugosidade com o tempo de tratamento - não seria a melhor abordagem.

Para orientar melhor os experimentos de caracterização, foi programada primeiramente uma série de experimentos qualitativos para avaliar:

\section{- Real eficácia do método proposto}

Dos métodos propostos, apenas um havia sido abordado de forma sistemática anteriormente.

Com estes experimentos simplificados esperava-se comprovar a real eficácia dos outros métodos propostos, aqui ainda avaliados de forma qualitativa;

\section{- Tempos de exposição mínimos e máximo}

Deseja-se saber para cada método, qual o tempo mínimo de exposição que produz resultados aparentes na peça e qual o tempo máximo de exposição que a peça apresenta melhorias de qualidade, sem que a mesma se deforme ou apresente outros defeitos que a descaracterizem.

- Estabilidade geométrica do CP

Deseja-se saber para cada teste e parâmetros utilizados se o CP reteve suas propriedades iniciais de massa e geometria.

\section{- Praticidade do método}

Com os experimentos, espera-se também encontrar dificuldades e particularidades dos métodos que os tornem mais ou menos práticos/viáveis para a comunidade que viria a se beneficiar do uso do mesmo.

Ao final dos experimentos de validação, seguindo estes critérios e comparando com as características intrínsecas do próprio processo de impressão, deseja-se aprovar ou descartar os métodos para uma análise detalhada posterior.

Métodos que requeiram aparatos complexos, gerem risco para o usuário, consumam muito solvente e etc. foram preteridos em favor de métodos mais simples e eficazes que ainda gerem resultados satisfatórios. 


\subsection{CARACTERIZAÇÃO DOS MÉTODOS SELECIONADOS}

Para a caracterização dos métodos selecionados foram fabricados diversos corpos de prova que tiveram inicialmente a rugosidade superficial da face inclinada medida.

Somente a face inclinada foi considerada devido a ser representativa do efeito staircase que compromete o acabamento superficial da peça.

$\mathrm{Na}$ sequência, os CPs foram identificados, separados por faixas de rugosidade e submetidos aos tratamentos selecionados.

Foram selecionados pontos de ensaio entre os valores mínimo e máximo de tempo obtidos para cada método.

Após a aplicação dos testes, a rugosidade na face inclinada de cada CP foi medida novamente.

Avaliou-se quantitativamente a redução percentual na rugosidade superficial em função do tempo de exposição para cada corrida experimental e para cada método. A finalidade foi encontrar uma correlação entre o tempo de tratamento e o resultado final a ser obtido dada a rugosidade inicial da peça.

Antes de se realizar os experimentos, foram utilizadas duas checagens prévias para validar a metodologia de medição:

\section{- Composição do erro experimental}

Mediu-se uma amostra cinco vezes sobre uma mesma linha na peça, sobre três linhas diferentes, a fim de se verificar se o instrumento de medida produzia resultados confiáveis e repetíveis em uma mesma linha da peça.

A peça foi medida no sentido em que as camadas foram sobrepostas, de forma a passar pelos picos e vales gerados pelo efeito staircase.

Esta metodologia visa determinar as contribuições relativas da incerteza instrumental e do erro aleatório na composição do erro experimental global associado às medidas de rugosidade do presente trabalho.

\section{- Comparação dos valores medidos com dados encontrados na literatura}

Com todos os valores de rugosidade para os CPs tabelados foi calculada a média dos resultados das medições. O valor obtido foi comparado com o dado fornecido por Galantucci et. al. (6). O principal objetivo dessa comparação é verificar a compatibilidade entre as medidas de rugosidade realizadas nas condições experimentais das investigações atuais com a obtida pelo grupo italiano. 


\section{RESULTADOS}

Nas próximas seções, mostra-se os procedimentos, resultados e análises obtidas na execução dos experimentos de validação dos métodos de ensaio propostos.

\subsection{EXPERIMENTOS EXPLORATÓRIOS}

Nesta seção são apresentados os resultados referentes aos experimentos exploratórios de caráter qualitativo mencionados anteriormente na seção metodologia.

Os critérios utilizados para a análise, a forma como a mesma foi conduzida estão descritas a seguir:

- Avaliação visual dos resultados;

Foi feita uma avaliação qualitativa dos resultados dos ensaios exploratórios levando em conta a aparência final da peça - acabamento, brilho, manchas, visibilidade do efeito staircase, etc. - assim como a mudança de percepção ao toque da superfície tratada. Para referência nas próximas seções, denota-se efetividade como uma avaliação visual positiva.

\section{- Tempos de exposição mínimos e máximo}

Para todos os métodos, estimou-se um valor inicial para um tempo de tratamento. Realizou-se um ensaio com esta duração e na sequência esse valor foi aumentado para uma amostra e reduzido para uma segunda amostra.

Repetiu-se até encontrar os limites inferiores e superiores para o tempo de tratamento, baseados em critérios de avaliação visual para o limite inferior e da estabilidade geométrica do CP para o limite superior.

\section{- Estabilidade geométrica do CP}

A estabilidade geométrica foi avaliada a partir da ocorrência de deformações aparentes.

Experimentos anteriores (6) demonstraram que a variação das medidas e massa das peças tratadas é insignificante, enquanto dentro dos limites do tempo de tratamento.

\section{- Praticidade do método;}

Foi feita uma avaliação sobre o uso do aparato experimental e sobre a implementação do método em situações fora do contexto de laboratório.

Foi levado em conta a complexidade do aparato experimental, a preparação para o ensaios, a dificuldade de se obter repetibilidade nos ensaios, o manuseio do CP após o tratamento, entre outros aspectos.

Nas seções seguintes são expostos os resultados da caracterização de cada um dos quatro métodos propostos. Para cada método, gerou-se uma tabela com o número da amostra tratada, o tempo de exposição, parâmetros específicos utilizados e uma análise do resultado geral do método. 


\subsubsection{MÉTODO DE IMERSÃO}

A Tabela 2 mostra para cada amostra qual foi o tempo de exposição e os resultados observados.

Tabela 2 - Resultados do experimento exploratório em imersão.

\begin{tabular}{|c|c|c|c|c|}
\hline Amostra & Tempo & & Observações & Avaliação Visual \\
\hline 1 & 15 & & & A textura permaneceu similar. Houve ligeiro aumento do brilho da peça \\
\hline 2 & 30 & $\mathrm{~s}$ & & Nota-se ligeira melhoria da rugosidade. Ligeiro aumento do brilho \\
\hline 3 & 60 & $\mathrm{~s}$ & & $\begin{array}{l}\text { Melhoria significativa da rugosidade. Peça quase lisa, não faz barulho tipico ao se } \\
\text { arrastar um objeto fino. O brilho deu lugar a uma texturização fosca. }\end{array}$ \\
\hline 4 & 120 & $\mathrm{~s}$ & & Progresso em relação a 3 \\
\hline 5 & 240 & $\mathrm{~s}$ & & Progresso em relação a 4. \\
\hline 6 & 480 & $\mathrm{~s}$ & Amoleceram as faces & Requer repetição com cura adequada. \\
\hline 8 & 600 & $\mathrm{~s}$ & Amoleceram as faces & Resultado visual excelente. Notam-se deformações devido ao manuseio antes da cura \\
\hline 9 & 12 & $\min$ & Amoleceram as faces & Após a cura, nota-se estufamento das faces. \\
\hline 12 & 15 & $\min$ & Amoleceram as faces & Estufou menos do que a amostra 9. Resultado visual não difere significativamente da \\
\hline 22 & 480 & $\mathrm{~s}$ & Amoleceram as faces & $\begin{array}{l}\text { Progresso em relação a } 5 \text {. Peça muito amolecida após remoção da solução. Requer } \\
\text { extremo cuidado no manuseio. }\end{array}$ \\
\hline 23 & 600 & $\mathrm{~s}$ & Amoleceram as faces & $\begin{array}{l}\text { Progresso em relação a 22. Ligeiro inchaço na face inclinada. Peça muito amolecida } \\
\text { após remoção da solução. Requer extremo cuidado no manuseio. }\end{array}$ \\
\hline 24 & 12 & $\min$ & Amoleceram as faces & $\begin{array}{l}\text { Não aparenta melhoria em relação a } 23 \text {. Ligeiro inchaço na face inclinada. Peça muito } \\
\text { amolecida após remoção da solução. Requer extremo cuidado no manuseio. }\end{array}$ \\
\hline 25 & 15 & $\min$ & Amoleceram as faces & $\begin{array}{l}\text { Não aparenta melhoria em relação a } 24 \text {. Ligeiro inchaço na face inclinada. Peça muito } \\
\text { amolecida após remoção da solução. Requer extremo cuidado no manuseio. }\end{array}$ \\
\hline
\end{tabular}

Observou-se que com menos de 30 segundos de imersão da peça não houve melhoria perceptível no acabamento. A partir dos 600 segundos de imersão as peças além de começarem a não apresentar uma melhoria perceptível na aparência final, passaram a se deformar durante a cura como mostra a Figura 23.

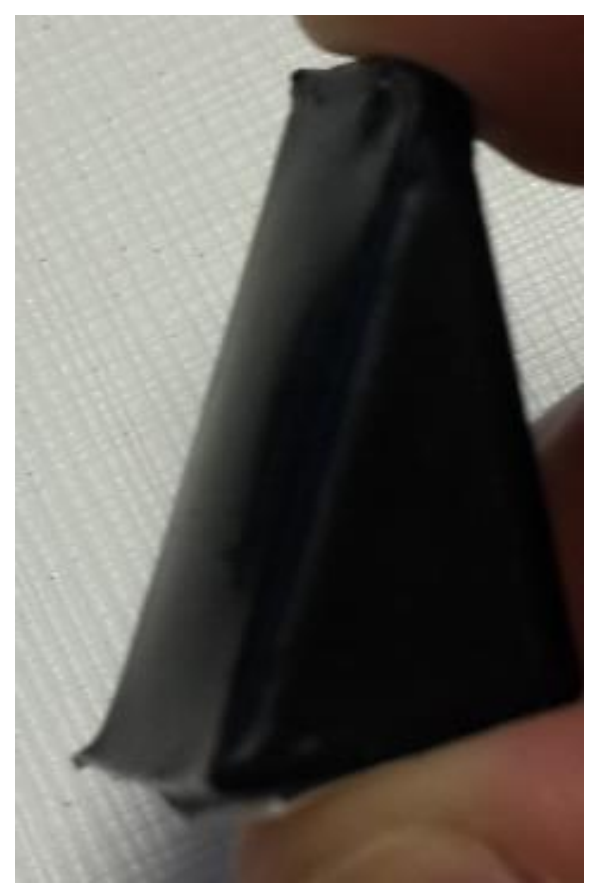

Figura 23 - Exemplo de amostra deformada.

Sugere-se que o estufamento observado na peça seja pela presença de vapor de acetona na parte interna da peça, forçando as faces já amolecidas a deformarem, o que implica que a pressão do vapor de acetona na parte interna da peça seja maior do que a pressão atmosférica. 
Esta observação não foi objeto de estudo deste trabalho, mas é forte candidata para um estudo futuro de como a espessura da peça se relaciona com o tempo de tratamento no quesito da estabilidade geométrica da peça tratada.

Nas peças expostas por períodos maiores também se viu a necessidade de extremo cuidado na manipulação do CP durante a retirada da solução e durante a cura. Qualquer contato com a superfície da peça gerava marcas permanentes na mesma.

Decidiu-se selecionar como ponto de corte inferior para os testes de caracterização deste método os 30 segundos de tratamento e para o ponto de corte superior os 600 segundos.

O método de imersão se mostrou pouco prático, devido às seguintes características:

- O tratamento de peças grandes requer um grande reservatório de solvente no qual seja possível submergir a peça por inteiro;

- A flutuabilidade da peça faz com que seja necessário escolher um ou mais pontos pelos quais deve-se forçar a peça a submergir, o que pode gerar marcar permanentes na peça;

- O amolecimento da peça durante o tratamento faz com que o processo de remoção da peça do solvente e a posterior cura seja muito sensível a quaisquer descuidos na manipulação da mesma.

Decidiu-se seguir com a caracterização quantitativa do mesmo, devido a possibilidade de comparação com o estudo realizado na área (6). 


\subsubsection{MÉTODO DE PVAP @ $21^{\circ} \mathrm{C}$}

A Tabela 3 mostra para cada amostra qual foi o tempo de exposição e os resultados observados.

Tabela 3- Resultados do experimento exploratório em Pvap @ $21^{\circ} \mathrm{C}$.

\begin{tabular}{|c|r|l|l|}
\hline Amostra Tempo & \multicolumn{1}{|c|}{ Observações } & \multicolumn{1}{c|}{ Avaliação Visual } \\
\hline \hline 7 & $30 \mathrm{~min}$ & & Nota-se brilho na peça e a rugosidade permanece inalterada. \\
\hline 10 & $60 \mathrm{~min}$ & Nota-se brilho na peça e a rugosidade reduz ligeiramente em relação à amostra 7. \\
\hline 11 & $120 \mathrm{~min}$ & Após a cura, houve deformação & $\begin{array}{l}\text { Brilho excelente. Houve deformação completa da peça após uma cura extremamente } \\
\text { demorada. }\end{array}$ \\
\hline 16 & $120 \mathrm{~min}$ & Após a cura, houve deformação & $\begin{array}{l}\text { Brilho excelente. Houve deformação completa da peça após uma cura extremamente } \\
\text { demorada. }\end{array}$ \\
\hline 26 & $90 \mathrm{~min}$ & Após a cura, houve deformação & $\begin{array}{l}\text { Brilho excelente. Houve deformação completa da peça após uma cura extremamente } \\
\text { demorada. }\end{array}$ \\
\hline 35 & $90 \mathrm{~min}$ & $\begin{array}{l}\text { A peça ficou perfeita ao contrario da amostra 26. Há suspeita de diferença no } \\
\text { filamento utilizado na amostra. Repetir o teste de 60 e 120 min. }\end{array}$ \\
\hline 36 & $60 \mathrm{~min}$ & Repetida com uso dos CPs corretos. & Nestas amostras observou-se uma melhoria gradual no acabemento da peça, tanto no \\
\hline 37 & $75 \mathrm{~min}$ & Repetida com uso dos CPs corretos. & brilho quando na rugosidade percebida. \\
\hline 38 & $90 \mathrm{~min}$ & Repetida com uso dos CPs corretos. & \\
\hline 42 & $120 \mathrm{~min}$ & Repetida com uso dos CPs corretos. & \\
\hline
\end{tabular}

Para este método de tratamento foi necessário se repetir algumas das corridas experimentais e adicionar novos pontos para melhor avaliação do método. Verificou-se nas amostras 11,16 e 26 um comportamento não compatível com as amostras 7 e 10. Atribuiu-se a diferença nos resultados a uma possível utilização de CPs fabricados em caráter de teste com filamento de ABS e configurações do software de fabricação que não as mesmas dos CPs dedicados aos experimentos.

Após novas aplicações do tratamento - realizados nas amostras 35, 36, 37, 38 e 42 - garantindo a utilização dos CPs corretos, obtiveram-se resultados consistentes onde não houve deformação das peças para o intervalo de tempo testado.

Este método se mostrou o mais simples e efetivo, produzindo amostras de qualidade visual elevada com um esforço mínimo e baixo uso do solvente. A manipulação da amostra após o tratamento é simples, bastase remover a tampa do volume no qual a peça se encontra e aguardar a cura total da mesma, depois da qual a peça pode ser manipulada normalmente.

Decidiu-se selecionar como ponto de corte inferior para os testes de caracterização deste método os 30 minutos de tratamento e para o ponto superior de corte 120 minutos. 


\subsubsection{MÉTODO DE PVAP @ $50^{\circ} \mathrm{C}$}

A Tabela 4 mostra para cada amostra qual foi o tempo de exposição e os resultados observados.

Tabela 4- Resultados do experimento exploratório em Pvap @ 50․

\begin{tabular}{|c|r|r|r|}
\hline Amostra & Tempo & Avaliação \\
\hline \hline 27 & 15 min & \\
\hline 28 & 30 min & \\
\hline 29 & 60 min & \\
\hline 30 & 75 min & Em geral estas corridas experimentais \\
\hline 31 & 90 min & apresentaram resultado de similar ou visualmente \\
\hline 32 & 75 min & pior do que as amostras tratadas a $21^{\circ}$ C por \\
\hline 33 & 60 min & durações de tratamento iguais. \\
\hline 34 & 90 min & \\
\hline 39 & 60 min & \\
\hline 40 & 75 min & \\
\hline 41 & 90 min & \\
\hline & & \\
\hline
\end{tabular}

Esperava-se inicialmente que devido ao aumento da temperatura de ensaio houvesse aumento na velocidade da dissolução do ABS, devido ao aumento da pressão de vapor.

Iniciaram-se os testes com um tempo mínimo de 15 minutos e progrediu-se para tempos de tratamento similares aos do método similar em temperatura ambiente.

Observou-se que os resultados do tratamento estavam aparentemente piores do que o método anterior. Decidiu-se repetir diversas vezes alguns dos pontos amostrais, como se observa na Tabela 4 , a fim de se confirmar os resultados.

Estes resultados contrariam a lógica utilizada para justificar a realização de ensaios similares em temperaturas diferentes: o aumento da temperatura do ensaio proveria, além de uma maior pressão de vapor, um aumento na velocidade de reação de dissolução do ABS.

Algumas possibilidades para explicar o fenômeno envolvem conhecer a curva de solubilidade de ABS em acetona em função da temperatura e a variação na resistência química do ABS em função da temperatura. Caso a solubilidade do ABS em acetona seja reduzida com o aumento da temperatura ou a resistência química aumente, o fenômeno poderia ser atribuído a um (ou ambos) os fatores. Dado que estes dados não estavam disponíveis, não foi possível confirmar as hipóteses.

Um trabalho futuro a fim de investigar o porquê dessa redução de efetividade seria possível e talvez fosse necessário realizar o levantamento das relações sugeridas no parágrafo anterior.

A decisão foi de que este método não seria inicialmente investigado, devido a menor efetividade aparente e a maior complexidade do aparato experimental. 


\subsubsection{MÉTODO DE EBULIÇÃO}

A Tabela 5 mostra para cada amostra qual foi o tempo de exposição e os resultados observados.

Tabela 5 - Resultados do experimento exploratório em ebulição.

\begin{tabular}{|c|c|c|c|c|c|}
\hline Amostra & Tempo & & T Mesa $\left[{ }^{\circ} \mathrm{C}\right]$ & Observações & Avaliação Visual \\
\hline 13 & & $\min$ & 120 & & Não se difere da amostra de referência \\
\hline 14 & 10 & $\min$ & 120 & & $\begin{array}{l}\text { Peça adquiriu brilho. Rugosidade reduzida } \\
\text { ligeiramente. }\end{array}$ \\
\hline 15 & 20 & $\min$ & 120 & $\begin{array}{l}\text { Faltou acetona, amostra inválida. } \\
\text { Decidiu-se reduzir a temperatura da } \\
\text { mesa }\end{array}$ & Brilho e redução significativa da rugosidade. \\
\hline 17 & 10 & $\min$ & 90 & & $\begin{array}{l}\text { Similar à amostra 14. Brilho menos intenso denota } \\
\text { efeito da redução da taxa de evaporação. }\end{array}$ \\
\hline 18 & 20 & $\min$ & 90 & & $\begin{array}{l}\text { Aumento no brilho da peça. Redução da rugosidade } \\
\text { em relação à amostra } 17\end{array}$ \\
\hline 19 & 5 & $\min$ & 90 & & Similar à amostra 13. \\
\hline 20 & 30 & $\min$ & 90 & & $\begin{array}{l}\text { Melhoria de rugosidade e brilho em relação à } \\
\text { amostra } 18\end{array}$ \\
\hline 21 & 40 & $\min$ & 90 & $\begin{array}{l}\text { Faltou acetona, amostra inválida. } \\
\text { Requer mudança no aparato } \\
\text { experimental. }\end{array}$ & \\
\hline
\end{tabular}

Nas primeiras amostras, 13 a 15 , utilizou-se uma temperatura de $120^{\circ} \mathrm{C}$ para a mesa aquecida, o que gerou uma alta taxa de evaporação da acetona do reservatório, causando um esgotamento prematuro da mesma. Observou-se efetividade no tratamento, mas a fim de não se modificar o aparato experimental, decidiu-se reduzir a temperatura da mesa e consequentemente a taxa de evaporação.

Após se reduzir a temperatura da mesa para $90^{\circ} \mathrm{C}$, visualizou-se uma melhoria contínua do acabamento com o aumento do tempo de exposição. Com tempos de exposição entre 30 e 40 minutos, houve esgotamento do reservatório de acetona. Decidiu-se não reduzir novamente a temperatura da mesa e nem se modificar o aparato experimental, devido aos bons resultados apresentados baseado nos critérios expostos no início desta seção.

Decidiu-se selecionar como ponto de corte inferior para os testes de caracterização deste método os 10 minutos de tratamento. Para o corte superior, em torno de 40 minutos, a depender do número de amostras a serem tratadas durante os experimentos de caracterização das amostras.

Apesar do aumento na complexidade do aparato experimental, o método não chega a ser impraticável, como demostra a própria comunidade de usuários das tecnologias de impressão 3D, mostrados na seção introdutória deste trabalho.

Em comparação ao método de Pvap @ $21^{\circ} \mathrm{C}$, há uma troca de complexidade do aparato experimental pela redução do tempo de exposição a atmosfera de solvente, sendo que a qualidade do resultado final é compatível entre os dois.

Possivelmente em um aparato dedicado para este tipo de tratamento, obtendo-se taxas maiores de evaporação do solvente, o tempo de tratamento seria ainda mais reduzido.

A manipulação da amostra após o tratamento é simples, basta-se remover a tampa do volume no qual a peça se encontra e aguardar a cura total da mesma, depois da qual a peça pode ser manipulada normalmente.

Decidiu-se prosseguir com a caracterização quantitativa deste método. 


\subsection{CARACTERIZAÇÃO DOS MÉTODOS}

O processo de caracterização dos métodos seguiu o fluxo apresentado na Figura 24

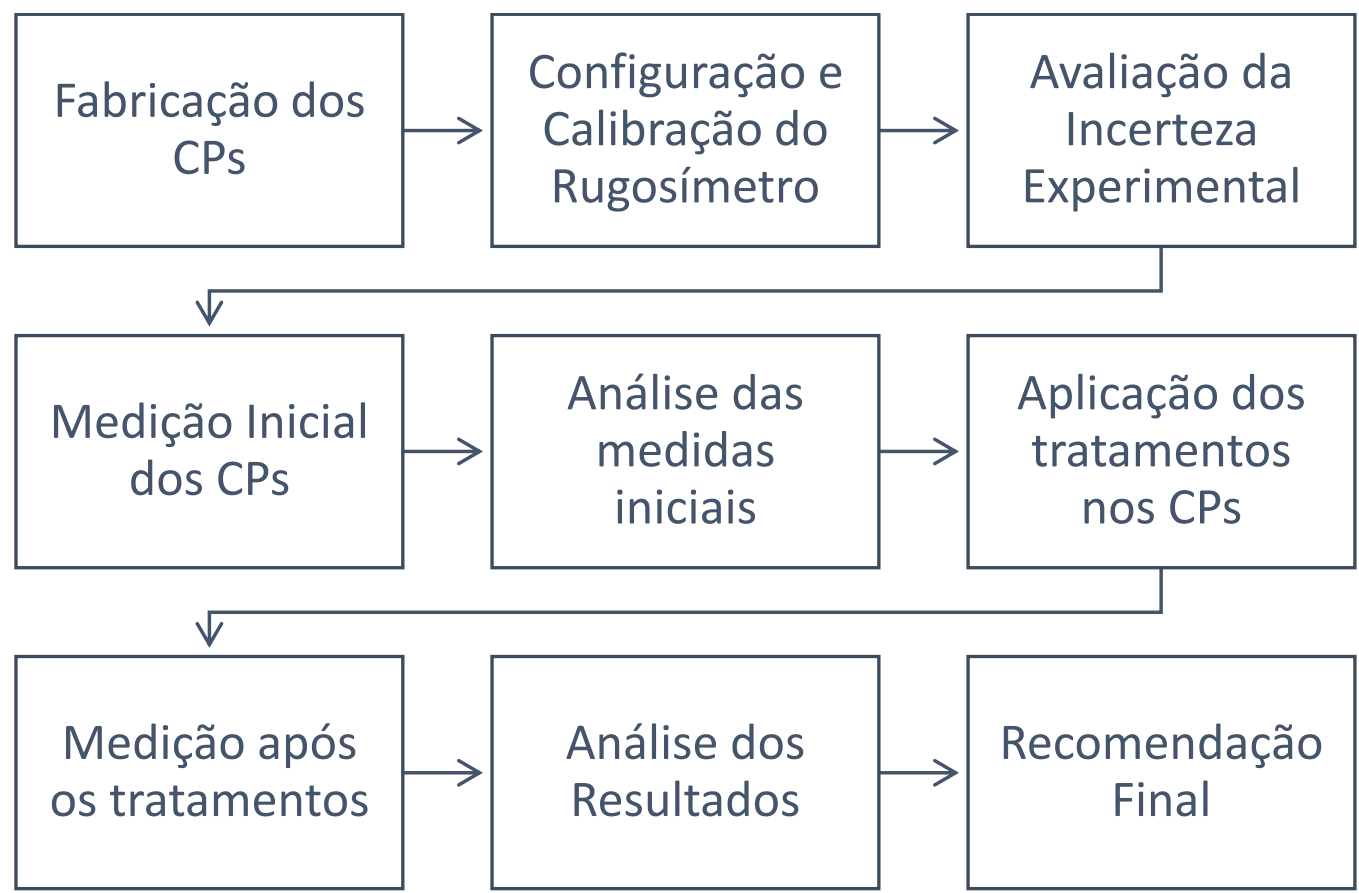

Figura 24- Fluxo da caracterização dos métodos.

Fabricaram-se os CPs conforme descrito na seção anterior e na sequência deu-se continuidade ao fluxo, com as etapas descritas nas próximas seções. 


\subsubsection{CONFIGURAÇÃO E CALIBRAÇÃO DO INSTRUMENTO DE MEDIDA}

Para a realização das medições, as peças foram posicionadas sobre uma mesa de desempeno enquanto o rugosímetro era suspenso em um traçador de altura. Para facilitar a realização das medições foi fabricado um gabarito de posicionamento dos CPs que pode ser visto na Figura 25:

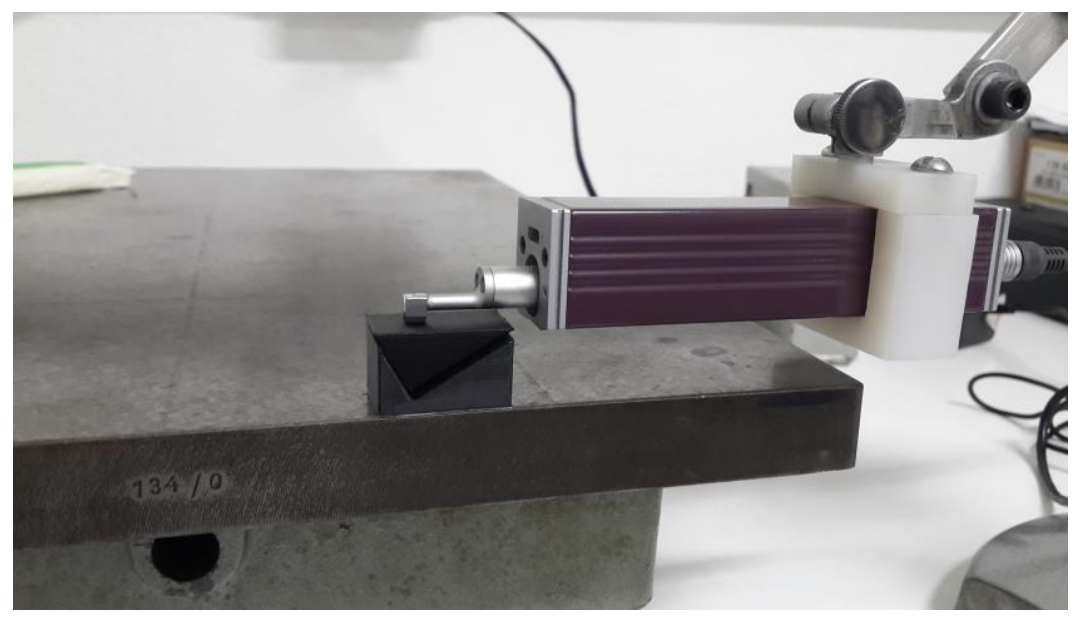

Figura 25 - Configuração para medição dos CPs.

Desta forma, pode-se garantir que as peças são medidas próximas da horizontal, que não há perda de contato entre a peça e o instrumento de medida e que o processo de posicionamento do CP não demande mais tempo do que o necessário, dado que seriam realizadas mais de 100 medições.

Seguindo as orientações do fabricante, para a seleção dos parâmetros de medida adequados, deve-se realizar uma medida preliminar para a seleção dos parâmetros corretos de medição. Para tal medida deve-se selecionar como parâmetros na medida da rugosidade um cutoff de $0,8 \mu \mathrm{mx}$ 5. Isto significa que a rugosidade será medida em cinco intervalos de $0.8 \mu \mathrm{m}$, medidos continuamente ao longo da linha de medição. $\mathrm{O}$ primeiro e o último intervalo são descartados para a elaboração da medida final.

Com o instrumento utilizado, após a varredura da peça é possível selecionar entre diversos padrões de rugosidade para a exibição da medida realizada. Para os fins desse experimento decidiu-se utilizar o parâmetro Ra de medida, que é a média aritmética dos valores absolutos medidos a partir de uma linha média de referência, de modo que se pode comparar os resultados com (6).

$\mathrm{O}$ resultado da primeira medição em um CP não tratado retornou um valor de $\mathrm{Ra}=12,78 \pm 0,01 \mu \mathrm{m}$, e de acordo com o fabricante para as medidas subsequentes deveria se adotar um Cut Off de 8mmx5, como explanado anteriormente. Devido a limitações do instrumento disponível, o máximo Cut Off disponível foi de 2,5mmx 5 , que foi adotado para as medições subsequentes. 


\subsubsection{AVALIAÇÃO DA INCERTEZA EXPERIMENTAL}

Desejava-se avaliar se o erro associado à medição seria dominado pela incerteza do instrumento ou por fatores aleatórios associados ao processo de fabricação e medição da peça, o erro aleatório.

Para tal escolheu-se aleatoriamente um CP não tratado e foram realizadas cinco medições sobre uma mesma linha da peça, como no arranjo da Figura 25. Fez-se as medições sobre três linhas diferentes da peça e os resultados são mostrados na Tabela 6.

Tabela 6 - Resumo das medidas de avaliação da incerteza experimental.

\begin{tabular}{|l|c|c|c|}
\hline & \multicolumn{3}{|c|}{ Medições de Ra [um] na Amostra 65 } \\
\hline & Linha 1 & Linha 2 & Linha 3 \\
\hline Medida 1 & 14.75 & 17.3 & 19.51 \\
\hline Medida 2 & 14.54 & 17.23 & 19.49 \\
\hline Medida 3 & 14.44 & 17.22 & 19.51 \\
\hline Medida 4 & 14.37 & 17.23 & 19.47 \\
\hline Medida 5 & 14.31 & 17.21 & 19.48 \\
\hline
\end{tabular}

Nota-se claramente que sobre uma mesma linha existe uma variação do resultado da medição uma ordem de magnitude acima da resolução do instrumento, que é de $0,01 \mu \mathrm{m}$.

Entre uma linha de medição e a outra, a variação da medida da rugosidade pode chegar a duas ordens de magnitude maior do que a resolução do instrumento de medição.

Com essas observações deseja-se mostrar que a incerteza experimental está definitivamente associada ao erro aleatório, atribuído ao processo de fabricação e medição da peça.

Assim, para as medidas subsequentes, será adotada qualquer linha de medição na peça como representativa da mesma, e apenas uma passagem de medição será realizada para avaliação da rugosidade, visto que a variação entre medidas é maior do que a precisão do instrumento e de acordo com a tabela oscila na escala de $0,1 \mu \mathrm{m}$, valor aqui considerado suficiente para as possíveis aplicações gerais dos métodos de tratamento. 


\subsubsection{MEDIÇÃO INICIAL DA RUGOSIDADE DOS CPS E ANÁLISE DOS RESULTADOS}

Foram medidos 69 corpos de prova para utilização nos ensaios de caracterização dos métodos.

O setup de medição utilizado foi o mesmo descrito na seção anterior e a tabela com todos os resultados pode ser encontrada anexa a este trabalho.

O gráfico da Figura 26 mostra a distribuição de rugosidades medidas, em $\mu$ m, para cada uma das 69 amostras:

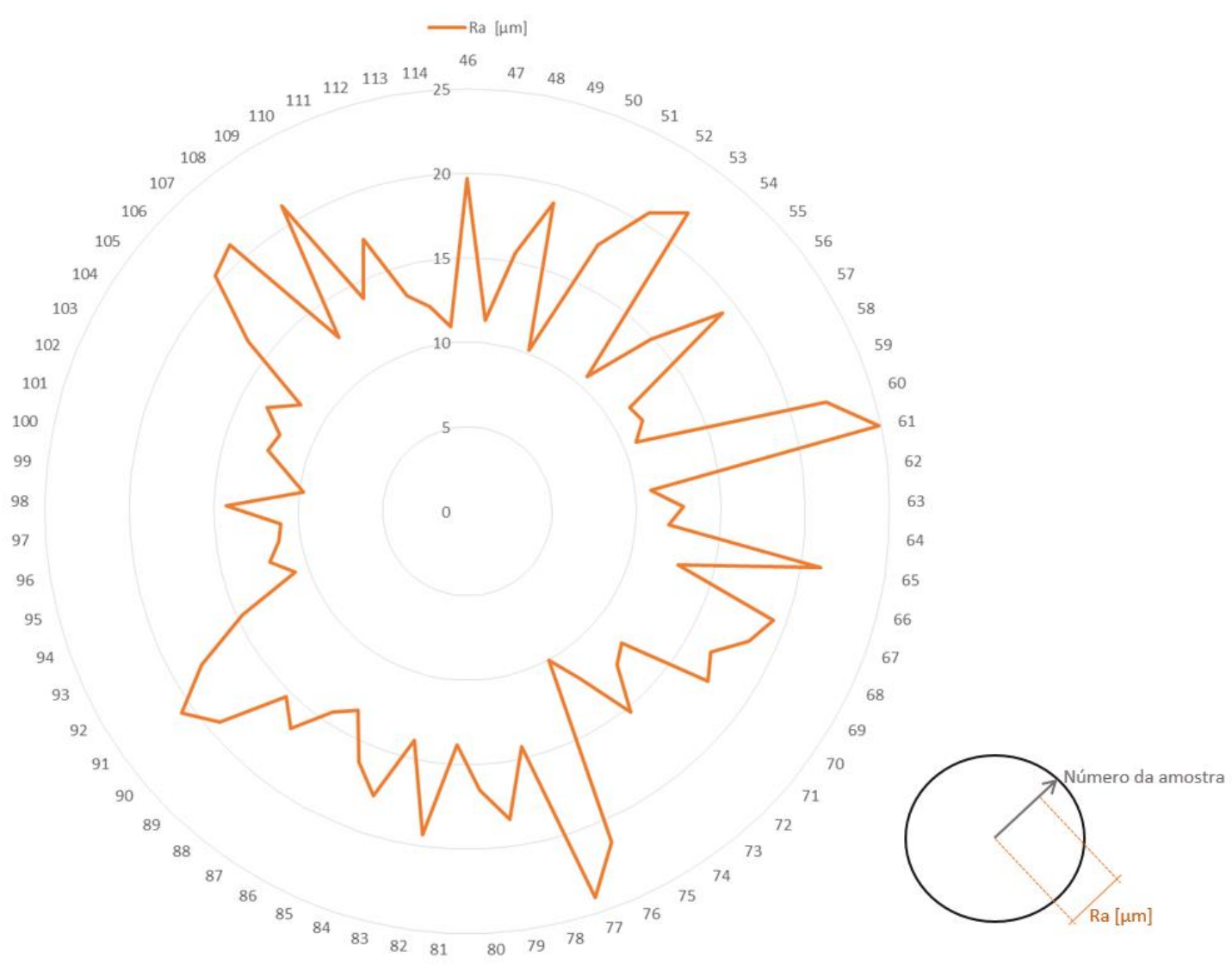

Figura 26 - Medida de rugosidade por amostra.

Como explanado na figura, traçando um raio no círculo, obtém-se no perímetro o número da amostra e a intersecção com a linha determina a medida realizada da rugosidade.

Pelo gráfico pode-se notar que há uma grande variação de rugosidade entre as amostras, novamente confirmando que existe uma grande aleatoriedade associada ao processo de fabricação.

A média de rugosidade medida para o conjunto foi de $15,39 \mu \mathrm{m}$, compatível com o encontrado no estudo utilizado como benchmark (6), que realizou medidas tanto com rugosímetros de contato, quanto com instrumentos de base óptica, e encontrou medidas compatíveis entre os dois instrumentos.

Dada essa variação de rugosidade entre amostras, decidiu-se então agrupar as amostras por rugosidade crescente, que resulta distribuição mostrada na Figura 27 e nos permite selecionar grupos de amostras com rugosidades similares. 


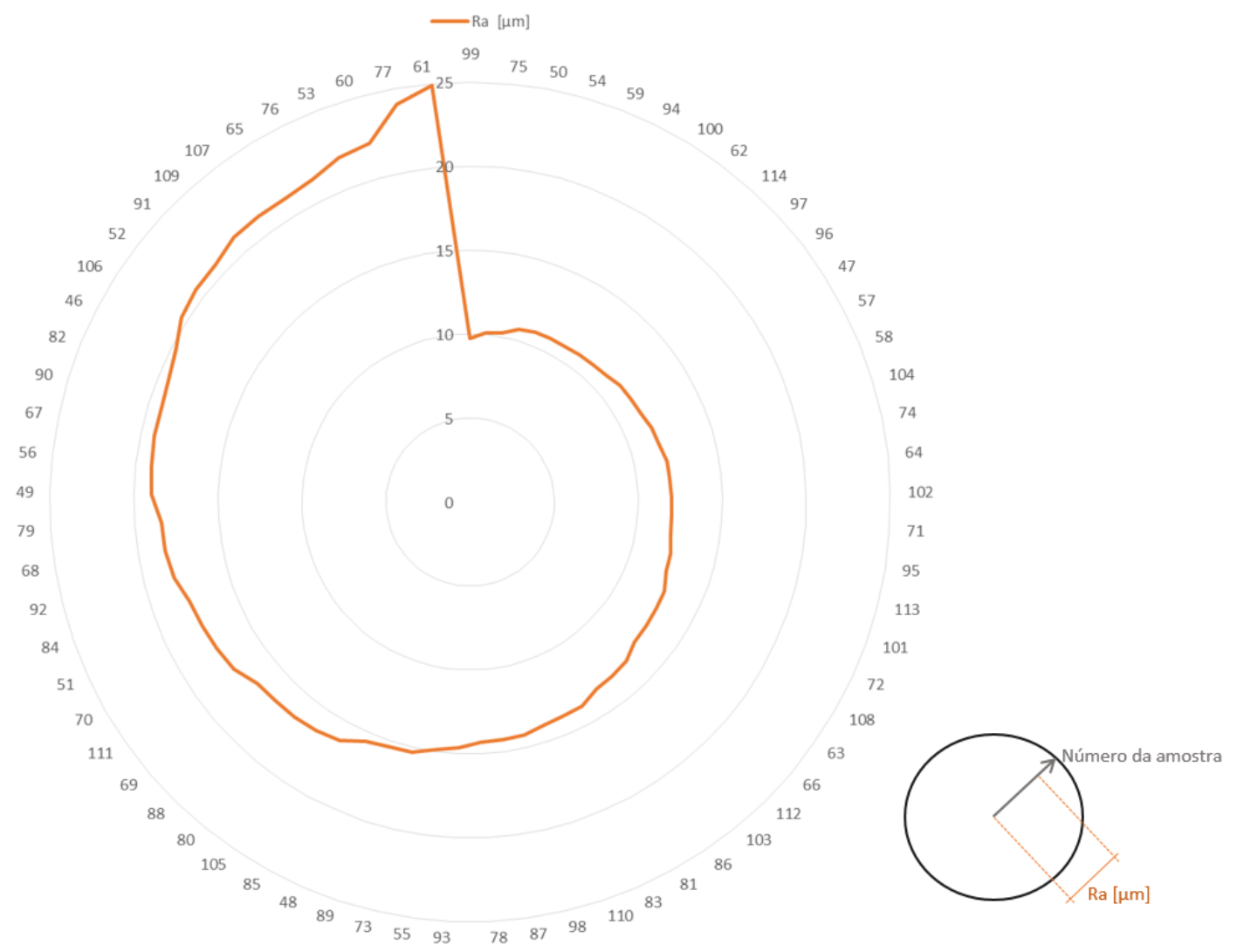

Figura 27 - Medidas de rugosidade para amostras ordenadas por ordem crescente de rugosidade.

Dessa forma pode-se notar que dentro do universo de amostras é possível selecionar subconjuntos que tenham a rugosidade próxima uma das outras. Isto é representado no gráfico ao se separar um setor circular que englobe um conjunto de amostras.

Assim, dividiram-se as amostras em grupos de dez unidades de forma que cada grupo tivesse uma pequena diferença de rugosidade entre a amostra mais rugosa e a menos rugosa, o que ficou na ordem de $10 \%$ para os grupos montados, como pode ser visto nas tabelas das seções subsequentes.

Para cada método de ensaio caracterizado utilizou-se um dos grupos de amostras para gerar as curvas para a caracterização do método em questão. 


\subsubsection{CARACTERIZAÇÃO DO MÉTODO DE IMERSÃO}

Foram realizados dez ensaios - como descrito anteriormente na seção de metodologia - com as amostras selecionadas, variando-se o tempo de imersão entre cada uma.

A Tabela 7 descreve para cada amostra, qual a duração da exposição ao solvente e as rugosidades medidas antes e após o tratamento, assim como a razão entre as mesmas.

Tabela 7- Resumo dos ensaios de caracterização do método de imersão.

\section{Primeira Rodada}

\begin{tabular}{|c|c|c|c|c|}
\hline Duração [s] & Amostra & Ra Antes [ $\mu \mathrm{m}]$ & Ra Depois [ $\mu \mathrm{m}]$ & Ra Antes/Ra Depois \\
\hline 30 & 99 & 9.76 & 3.51 & $278 \%$ \\
\hline 60 & 75 & 10.09 & 3.59 & $281 \%$ \\
\hline 90 & 50 & 10.2 & 2.76 & $370 \%$ \\
\hline 120 & 54 & 10.66 & 2.95 & $361 \%$ \\
\hline 180 & 59 & 10.8 & 2.92 & $370 \%$ \\
\hline 240 & 94 & 10.83 & 2.74 & $395 \%$ \\
\hline 300 & 100 & 10.84 & 3.46 & $313 \%$ \\
\hline 360 & 62 & 10.9 & 2.02 & $540 \%$ \\
\hline 480 & 114 & 10.98 & 2.33 & $471 \%$ \\
\hline 600 & 97 & 11.06 & 2.64 & $419 \%$ \\
\hline
\end{tabular}


resultados.

O gráfico da Figura 28 expõe as mesmas informações de uma forma que favorece a análise de parte dos

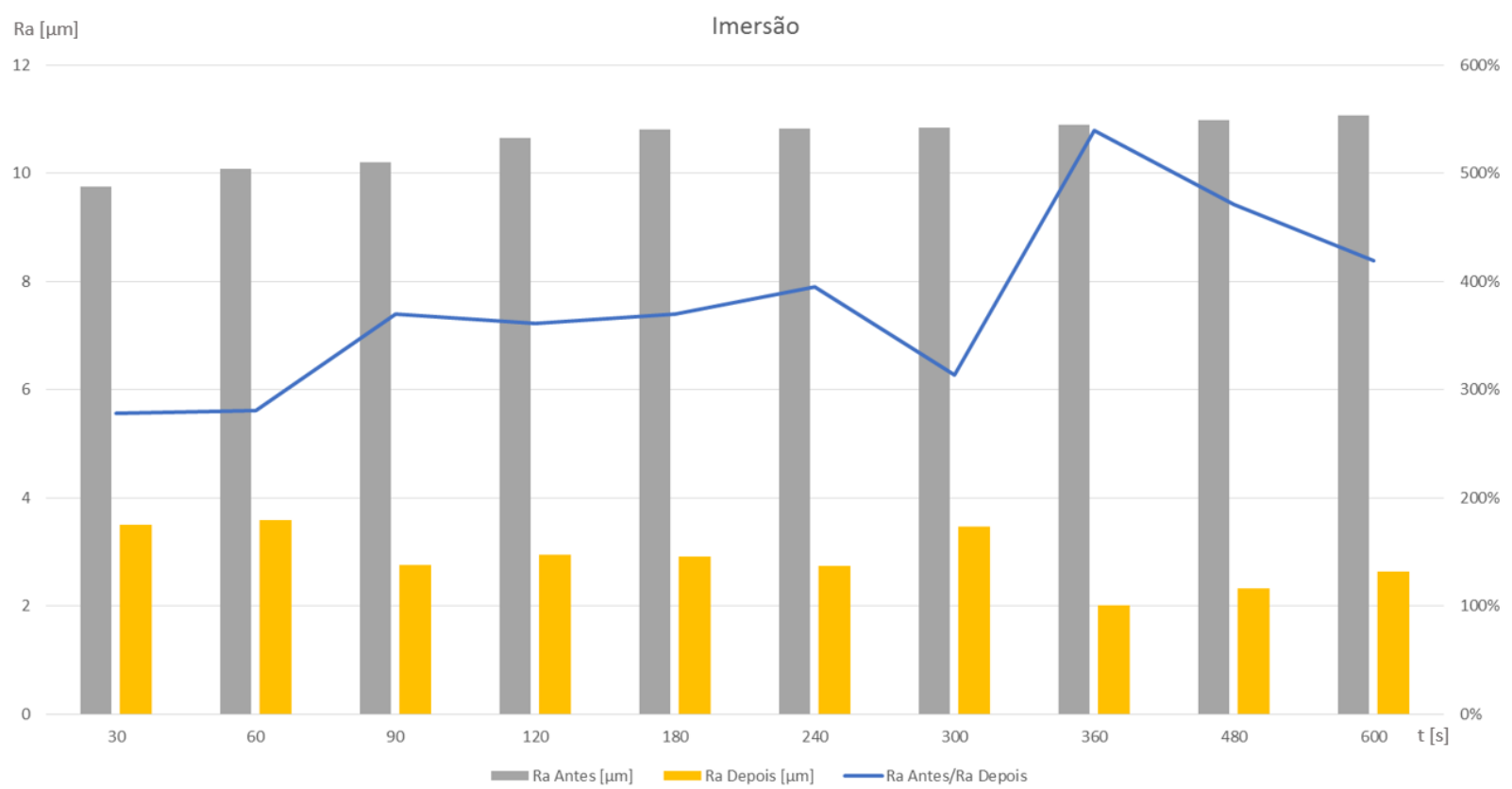

Figura 28 - Resultados da caracterização do método de imersão.

Percebe-se claramente que o método promove uma redução significativa da rugosidade da amostra e que mesmo se aumentando o tempo de exposição, os resultados finais tendem a se concentrar na faixa entre $2 \mathrm{e}$ $4 \mu \mathrm{m}$ de rugosidade final.

Como a rugosidade inicial varia de amostra para amostra, analisando a linha que representa a variação da razão de rugosidades temos a falsa impressão de uma ausência de padrão no resultado.

O que se pode perceber na realidade é a estagnação do resultado final que pode observado nas barras amarelas: mesmo se aumentando o tempo de exposição as amostras tendem à um patamar inferior de rugosidade.

Este fenômeno pode estar associado a formação de um filme de acetona saturada de ABS que age como interface entre a peça e a acetona não saturada, como representado na Figura 29.

\section{Acetona Não-Saturada}

\section{Solução Saturada de ABS em Acetona}

\section{Corpo de Prova}

Figura 29 - Representação da saturação da acetona em contato com o CP.

Associa-se a ocorrência de tal fenômeno ao caráter estático do tratamento, ou seja, à ausência de movimentação tanto do CP quanto do solvente, que favorece que se alcance qualquer regime de equilíbrio. 
Adicionando movimento à peça ou agitando o recipiente - possivelmente em uma mesa vibratória haveria uma circulação do solvente e possivelmente observar-se-ia um novo patamar inferior de rugosidade ou a ausência do mesmo.

Cabem futuras investigações aqui, possivelmente se realizando uma circulação sutil do solvente dentro do recipiente de tratamento, mas que neste momento ficam fora do escopo deste trabalho. 


\subsubsection{CARACTERIZAÇÃO DO MÉTODO DE PVAP @ $21^{\circ} \mathrm{C}$}

Foram realizados dez ensaios - como descrito anteriormente na seção de metodologia - com as amostras selecionadas, variando-se o tempo de tratamento entre cada uma.

A Tabela 8 descreve para cada amostra, qual a duração da exposição ao solvente e as rugosidades medidas antes e após o tratamento, assim como a razão entre as mesmas.

Tabela 8 - Resumo dos ensaios de caracterização do método de Pvap @ $21^{\circ} \mathrm{C}$.

\begin{tabular}{|c|c|c|c|c|}
\hline \multicolumn{5}{|c|}{ Primeira Rodada } \\
\hline Duração [min] & Amostra & Ra Antes & Ra Depois & Ra Antes/Ra Depois \\
\hline \hline 30 & 113 & 12.3 & 3.29 & $374 \%$ \\
\hline 40 & 101 & 12.35 & 2.76 & $447 \%$ \\
\hline 50 & 72 & 12.71 & 2.67 & $476 \%$ \\
\hline 60 & 108 & 12.75 & 2.23 & $572 \%$ \\
\hline 70 & 81 & 13.85 & 2 & $693 \%$ \\
\hline 80 & 66 & 12.86 & 1.7 & $756 \%$ \\
\hline 90 & 112 & 13.26 & 1.6 & $829 \%$ \\
\hline 100 & 103 & 13.36 & 1.53 & $873 \%$ \\
\hline 110 & 86 & 13.43 & 1.37 & $980 \%$ \\
\hline 120 & 63 & 12.8 & Perda de estabilidade geométrica \\
\hline
\end{tabular}

Os dados expostos deixam claro que o método ensaiado traz resultados favoráveis, com uma evolução contínua dos resultados até patamares elevados de redução da rugosidade, como exposto na coluna que mostra as razões entre as rugosidades inicial e final.

Dos dez ensaios apenas uma das amostras foi descartada devido a perda de estabilidade geométrica, caracterizado pelo estufamento do $\mathrm{CP}$, conforme mostra a Figura 30 onde se nota um abaulamento da face inclinada.

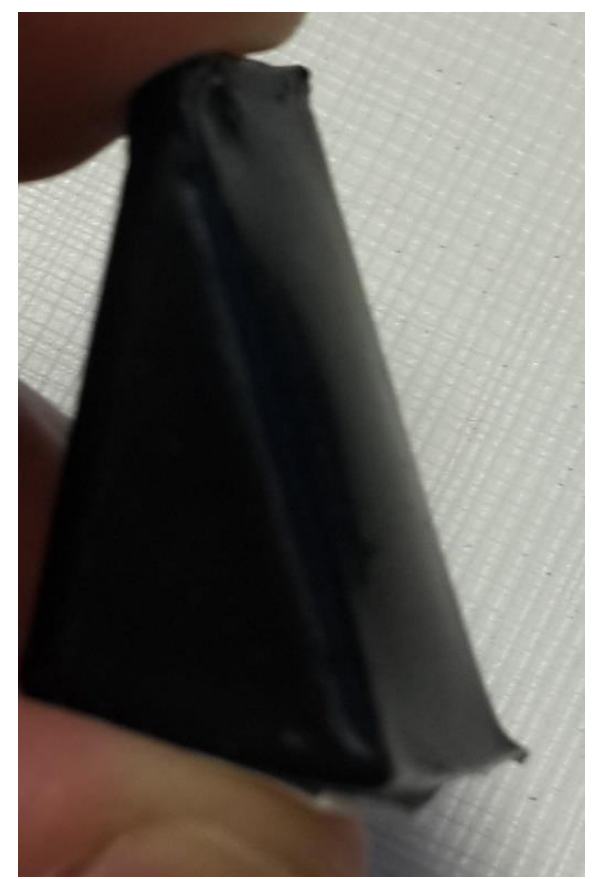

Figura 30 - Deformação da amostra 63. 
Este resultado não significa que exista um patamar superior próximo a 120 minutos para o tratamento de qualquer peça, supõe-se que a espessura da parede do objeto sendo tratado influencie no tempo máximo admissível de exposição.

Pode-se explicar esse fenômeno com hipótese que a exposição prolongada da peça ao vapor de acetona haja uma difusão do solvente para o interior do CP e logo uma pressão de vapor do mesmo no interior da peça. Com as faces amolecidas devido ao tratamento, a diferença de pressão entre o exterior e o interior da peça causaria o estufamento da mesma. Esta hipótese não foi verificada durante a execução deste trabalho, podendo futuramente ser alvo de um novo estudo.

O gráfico da Figura 31 expõe as informações da Tabela 8 de uma forma que favorece a análise de parte dos resultados.

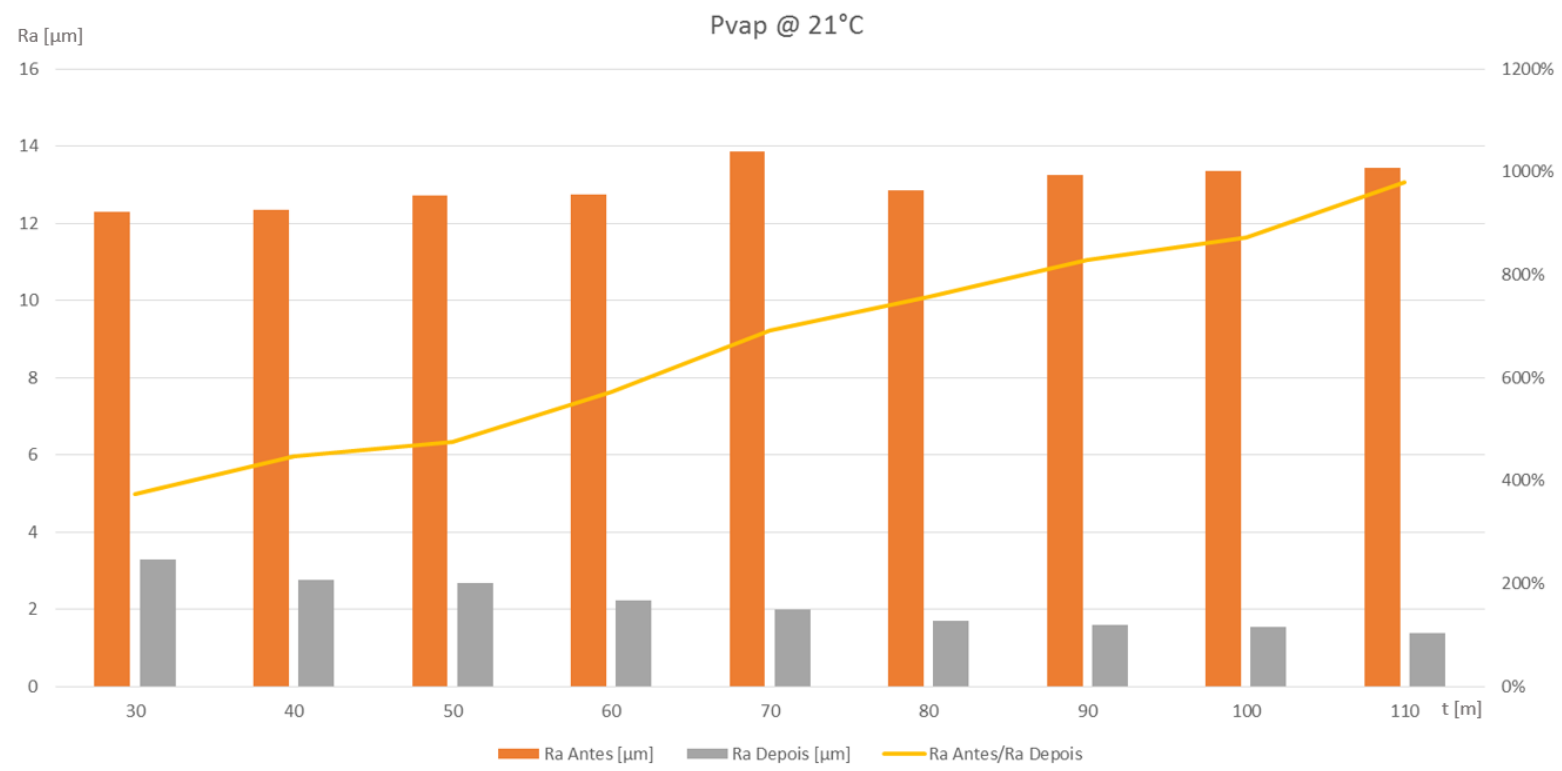

Figura 31 - Resultados da caracterização do método de Pvap @ $21^{\circ} \mathrm{C}$.

De forma preliminar e intuitiva, podemos notar um comportamento aparentemente linear para a evolução da rugosidade com o tempo ao observarmos o parâmetro Ra Depois, que ao contrário do experimento com a imersão do CP, não demonstra a existência de um patamar inferior de rugosidade.

Neste gráfico, novamente atentando para os dados representados pelas barras cinzas, também pode-se levantar dois pontos importantes:

- É possível realizar um ajuste dos dados experimentais à uma curva que permita estimar a taxa de redução da rugosidade;

- Os menores valores de rugosidade medidos estão na mesma ordem de grandeza que variação de medidas entre linhas, como exposto na Tabela 6;

A partir do conjunto de dados experimentais, fez-se um ajuste linear do parâmetro Ra Depois a fim de se obter a taxa de redução da rugosidade superficial na janela de tempo aonde se realizaram as medições.

O valor obtido foi de $\mathbf{- 0 . 0 2 3 4} \boldsymbol{\mu m} / \mathbf{m i n}$ com um coeficiente de correlação de Pearson, $\mathbf{r}^{2}$, no valor de 0.948, indicando válida uma correlação linear para esta janela de tempo, o que nos permite já com estes resultados experimentais aplicar o método para uso.

Claramente esta relação não se mantém linear para tempos menores do que trinta minutos, visto que a redução de rugosidade que ocorre durante a primeira meia hora, $\sim 9 \mu \mathrm{m}$, é muito maior do que nos próximos 80 minutos, $\sim 2 \mu \mathrm{m}$ e que um modelo linear eventualmente resultaria em rugosidade zero, o que não tem significado físico.

Estima-se que quando o comportamento desse tratamento for avaliado de forma completa, partindo dos primeiros segundos de tratamento até um tempo suficientemente grande, se observe um comportamento não linear e assimptótico em direção a um limite inferior de rugosidade, dado que não haja uma perda da estabilidade geométrica da peça. 
Isto implica também que a taxa de redução da rugosidade diminua com o aumento do tempo de tratamento, o que significa que para se atingirem rugosidades cada vez menores, o tempo de tratamento aumenta de forma significativa.

Pontua-se aqui que devido a razão entre o erro aleatório observado e a ordem de grandeza das rugosidades medidas após o tratamento, tentar refinar o modelo de ajuste de curva para o conjunto de dados disponíveis não traria maior significância do que o ajuste proposto, mesmo que os parâmetros de correlação fossem ligeiramente maiores.

Para se verificar a hipótese levantada da existência de um comportamento não linear sugere-se um estudo futuro com a realização de medições com o uso de um instrumento de medição sem contato que avalie a rugosidade baseada em uma área da peça e não apenas em uma linha, desta forma o comportamento aleatório da fabricação da peça estaria contemplado na própria medição e ultimamente a composição do erro experimental poderia ser atribuída estritamente ao instrumento de medida utilizado, trazendo mais confiança para a análise dos resultados. 


\subsubsection{CARACTERIZAÇÃO DO MÉTODO DE EBULIÇÃO}

Foram realizados dez ensaios - como descrito anteriormente na seção de metodologia - com as amostras selecionadas, variando-se o tempo de imersão entre cada uma.

A Tabela 9 descreve para cada amostra, qual a duração da exposição ao solvente e as rugosidades medidas antes e após o tratamento, assim como a razão entre as mesmas.

Tabela 9 - Resumo dos ensaios de caracterização do método de ebulição

\section{Primeira Rodada}

\section{Duração [min] Amostra Ra Antes [ $\mu \mathrm{m}]$ Ra Depois [ $\mu \mathrm{m}]$ Ra Antes/Ra Depois}

\begin{tabular}{|l|c|c|c|c|}
\hline \hline 10 & 85 & 16.17 & 15.65 & $103 \%$ \\
\hline 13 & 105 & 16.41 & 14.96 & $110 \%$ \\
\hline 16 & 80 & 16.54 & 12.65 & $131 \%$ \\
\hline 19 & 88 & 16.55 & 4.01 & $413 \%$ \\
\hline 22 & 69 & 16.64 & 3.71 & $449 \%$ \\
\hline 25 & 111 & 17.22 & 3.47 & $496 \%$ \\
\hline 28 & 70 & 17.41 & 2.59 & $672 \%$ \\
\hline 31 & 51 & 17.57 & 2.71 & $648 \%$ \\
\hline 34 & 84 & 17.73 & 3.61 & $491 \%$ \\
\hline 37 & 92 & 18.15 & \multicolumn{2}{|c|}{ Não Realizado } \\
\hline
\end{tabular}


O gráfico da Figura 32 expõe as informações da Tabela 8 de uma forma que favorece a análise de parte dos resultados.

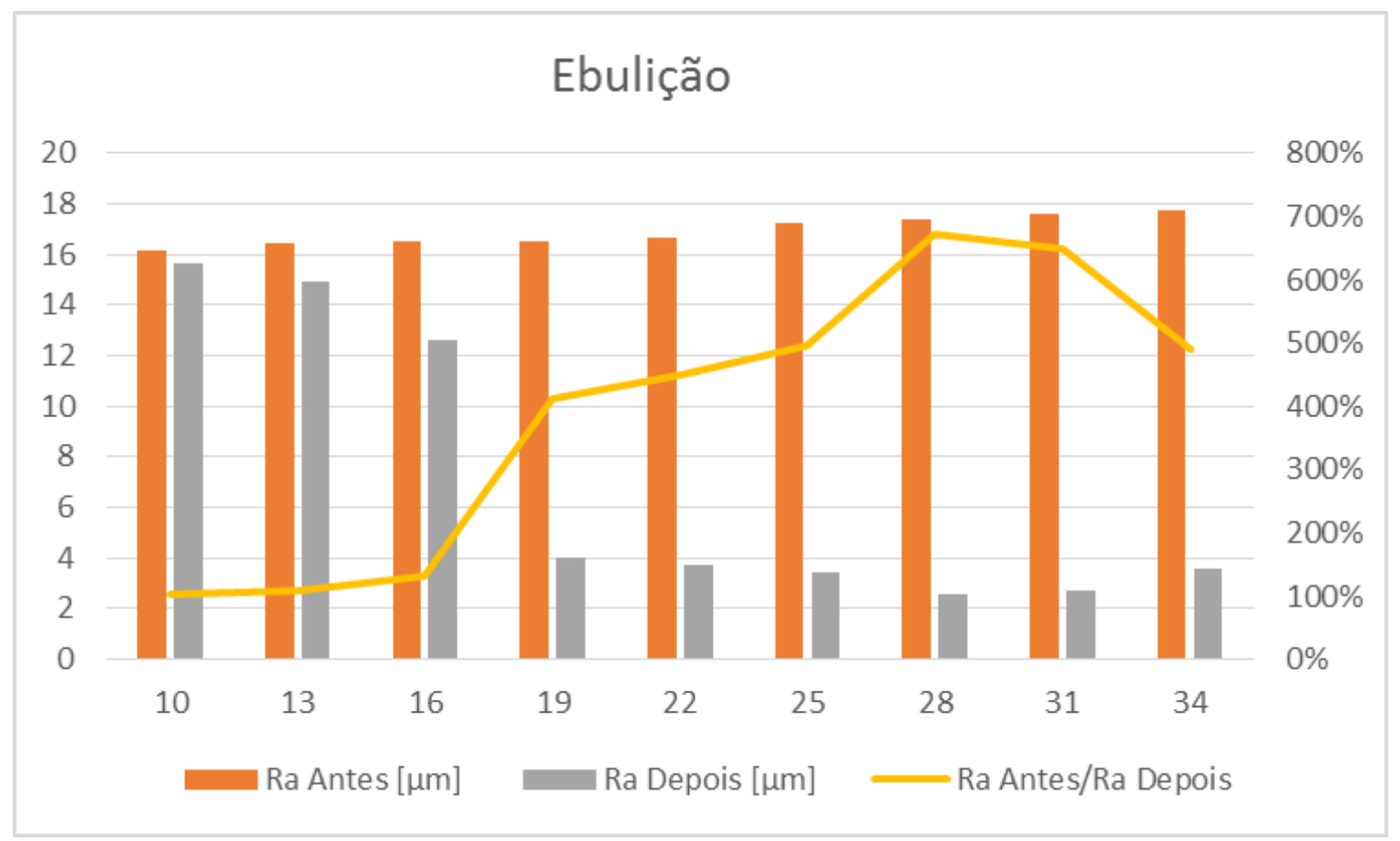

Figura 32 - Resultados da caracterização do método de ebulição.

Neste experimento se observa a maior variação entre o comportamento esperado e o observado ao se olhar para tanto para o parâmetro Ra Depois.

Inicialmente se observa uma redução muito lenta da rugosidade, seguida de uma abrupta queda na mesma entre a amostra 16 e 19. Entre as amostras 19 e 28 temos o que parece ser um comportamento linear durante alguns minutos, para depois observar um aumento da rugosidade nas amostras 31 e 34 .

Dividindo o gráfico em três zonas podemos realizar uma análise por janelas temporais:

\section{- De 10 a 16 minutos}

Supõe-se que aqui a taxa de redução da rugosidade é pequena devido a quantidade de vapor de solvente dentro do aparato experimental. A taxa de evaporação da acetona, controlada aqui pela temperatura da mesa aquecida, deve influenciar no resultado observado nos primeiros pontos de teste. Isso se traduz em uma maior potência de aquecimento do solvente e consequentemente na necessidade de um maior reservatório de solvente para tempos de tratamento maiores;

\section{- De 19 a 28 minutos}

Aqui se observa o comportamento esperado inicialmente, onde um tempo maior de exposição ao tratamento se traduz em uma redução controlada da rugosidade da peça.

Dado que, em geral, os resultados encontrados no método não são tão favoráveis quanto os observados no método Pvap@ $21^{\circ} \mathrm{C}$ decidiu-se não realizar nenhum tipo de ajuste de curvas a fim de se caracterizar o comportamento nesta fase do experimento.

\section{- De 31 a 34 minutos}

Aqui se observa uma aparente piora na efetividade do tratamento, avaliado pelas rugosidades finais das amostras 31 e 34, que pode ser justificado por duas razões diferentes.

A amostra tratada por 31 minutos possuía uma rugosidade aproximadamente $0,15 \mu \mathrm{m}$ maior do que a amostra anterior e apresentou uma diferença de redução na rugosidade de $0,1 \mu \mathrm{m}$, em relação a amostra anterior. Quando comparados ao erro experimental, esses valores tornam essa aparente redução na efetividade inconclusiva.

Para se obter uma análise melhor dessa região, deve-se realizar experimentos com menor intervalo de tempo entre as amostras a fim de se aumentar a resolução da curva obtida. 
O uso de aparatos de medição sem contato e com medição por área possivelmente ajudariam a esclarecer melhor o fenômeno. Novamente, não faz parte do escopo deste trabalho esta investigação, sendo necessário um trabalho futuro aqui.

Para a amostra de 34 minutos a explicação do resultado não satisfatório se dá nas limitações do aparato experimental visto que o reservatório de acetona se esgotou antes do término do tratamento. Pelo mesma razão o ensaio com a amostra que seria tratada por 37 minutos não foi realizado.

Seria necessário se repetir todas as rodadas de teste fazendo o uso de outro arranjo experimental para continuar caracterizando este método para tempos maiores do que 31 minutos. Tal atividade não foi escopo deste trabalho e poderia ser feita conjuntamente com as medições propostas anteriormente. 


\section{CONCLUSÃO}

Neste trabalho foram avaliados inicialmente quatro métodos para a redução da rugosidade superficial de peças de ABS fabricadas por processos aditivos.

O controle da rugosidade superficial de peças deste tipo traz uma série de benefícios para diversos grupos de usuários da tecnologia, incluindo fabricação de modelos reduzidos para análises de interação fluido-estrutura, uso biomédico, moldes de fundição, protótipos de alta qualidade, entre diversos outros.

Após a definição metodológica foram realizados experimentos exploratórios para verificar o comportamento dos quatro processos selecionados previamente. Destes quatro processos, apenas um foi descartado por apresentar performance inferior a um método similar que requer um aparato experimental mais simples.

Na sequência se caracterizou cada um dos outros três métodos através do levantamento das relações entre o tempo de tratamento, a rugosidade inicial e a rugosidade final do corpo de prova.

Durante a caracterização do método de imersão da peça se observou uma redução significativa da rugosidade da peça, seguido de uma estagnação na redução, possivelmente associada a saturação do filme de solvente em contato com a peça. Sugeriu-se a realização de estudo adicional com a recirculação do solvente ou com uso de uma mesa vibratória para promover a movimentação sutil do solvente.

Este método se mostrou pouco prático para tratamento em peças volumosas, dado o grande uso de solvente necessário, dos problemas associados a flutuabilidade da peça e da manipulação da peça sem causar danos permanentes após o fim do tratamento da superfície.

Na caraterização do método de ebulição novamente foi observada uma redução significativa da rugosidade e em parte dos pontos experimentais pode se observar uma tendência de uma redução controlada com comportamento aparentemente linear.

Neste método, o aparato experimental teve um papel significativo nos resultados encontrados, tanto na caraterística do regime transiente inicial, que devido ao tempo inicial de tratamento escolhido e do intervalo de amostras não foi possível de ser caracterizado. Na outra ponta dos tempos de realização do tratamento, novamente a influência do aparato pode ser percebida com o esgotamento do solvente a ser evaporado.

Sugere-se realizar novo estudo com o uso de um aparato mais elaborado e com menor intervalo entre os tempos de tratamento a fim de se obter uma resolução melhor dos resultados.

A caracterização que retornou os resultados mais promissores foi referente ao método denominado Pvap @ $21^{\circ} \mathrm{C}$.

O método além de requerer um aparato experimental simples, pouco uso do solvente e facilitar a manipulação da peça tratada, produz resultados previsíveis com uma duração do tempo de tratamento compatível com a escala de tempo da fabricação das peças e uma rugosidade final baixa.

Durante a janela de tempo no qual se fizeram os ensaios, se observou um comportamento aproximadamente linear, com uma taxa de redução da rugosidade de $\mathbf{- 0 . 0 2 3 4} \boldsymbol{\mu m} / \mathbf{m i n}$ com um coeficiente de correlação de Pearson, $\mathbf{r}^{2}$, no valor de $\mathbf{0 . 9 4 8}$, indicando válida correlação linear para esta janela de tempo.

Considerou-se esse método ideal para concentração dos estudos futuros, preferencialmente se iniciando por uma caracterização com uma menor janela de tempo entre as amostras e se iniciando com tempos pequenos de tratamento.

Conforme dito anteriormente, se prevê que quando caracterizada desta forma, a curva de rugosidade em função do tempo tenha um comportamento não linear e assimptótico, com um grande redução de rugosidade nos primeiros minutos de tratamento, seguido de um comportamento similar ao observado no intervalo analisado neste estudo e finalmente uma estabilização da redução da rugosidade em um regime assimptótico.

Recomenda-se ainda o uso de outros instrumentos de medição que não os rugosímetros de contato, a fim de se reduzir a incerteza experimental, que para este estudo, por vezes esteve na ordem de grandeza dos próprios resultados encontrados. 


\section{REFERÊNCIAS}

1. D.T. Pham, R.S. Gault. A comparison of rapid prototyping technologies. International Journal of Machine Tools \& Manufacture. 1998, Vol. 38, 10-11.

2. Gershenfeld, Neil. How to Make Almost Anything - The Digital Fabrication Revolution. Foreign Affairs. 2012.

3. Crump, S. Scott. Apparatus and method for creating three-dimensional objects . US5121329 A US, 30 de October de 1989. Grant.

4. RepRap. RepRap. [Online] http://reprap.org/.

5. Yonghua Chen, Jianan Lu. RP part surface quality versus build orientation: when the layers are getting thinner. The International Journal of Advanced Manufacturing Technology. 2013, Vol. 67, 1-4.

6. L.M. Galantucci, F. Lavecchia, G. Percoco. Experimental study aiming to enhance the surface finish of fused deposition modeled parts. CIRP Annals - Manufacturing Technology. 2009, Vol. 58, 1, pp. 189-192.

7. L. M. Galantucci, Michele Dassisti, F. Lavecchia, G. Percoco. Improvement of fused deposition modelled surfaces through milling and physical vapor deposition. s.l. : Dipartimento di Meccanica, Matematica e Management, Politecnico di Bari.

8. L.M. Galantucci (1)*, F. Lavecchia, G. Percoco. Compressive Properties of FDM Rapid Prototypes Treated with a Low Cost Chemical Finishing. Research Journal of Applied Sciences, Engineering and Technology. 2012, Vol. 4, 19, pp. 3838-3842.

9. L.M. Galantucci, F. Lavecchia, G. Percoco. Quantitative analysis of a chemical treatment to reduce roughness of parts fabricated using fused deposition modeling. CIRP Annals - Manufacturing Technology. 2010, Vol. 59, 1, pp. 247-250.

10. Anoop Kumar Sood, R.K. Ohdar, S.S. Mahapatra,. Improving dimensional accuracy of Fused Deposition Modelling processed part using grey Taguchi method. Materials \& Design. 2009, Vol. 30, 10.

11. Ahn DK, Kim HC, Lee SH. Fabrication Direction Optimization to Minimize Post-Machining in Layered Manufacturing. International Journal of Machine Tools and Manufacture. 2007, Vol. 47, 3-4.

12. Kumar M, Choudhury AR. Adaptive Slicing with Cubic Patch Approximation. Rapid Prototyping Journal. 2002, Vol. 8, 4.

13. Lan P, Chou S, Chent L, Gemmilt D. Determining Fabrication Orientations for Rapid Prototyping with Stereolithography Apparatus. Computer-Aided Design. 1997, Vol. $29,1$.

14. Mani Ka, Kulkarni Pa, Dutta Da. Region-Based Adaptive Slicing. Computer-Aided Design. 1999, Vol. $31,5$.

15. Thrimurthulu K, Pandey P, Reddy N. Optimum Part Deposition Orientation in Fused Deposition Modelling. Optimum Part Deposition Orientation in Fused Deposition Modelling. 2004, Vol. 44, 6.

16. N.N. Kumbhar, A. V. Mulay. Post processing methods used to improve surface finish of products which are manufactured by Additive Manufacturing tecnhologies - A review. s.l. : Pune College of Engineering, 2005.

17. Pulak M. Pandey, N. Venkata Reddy, Sanjay G. Dhande. Improvement of surface finish by staircase machining in fused deposition modeling. Journal of Materials Processing Technology. 2003, Vol. 132, 1-3.

18. M. Fischer, V. Schöppner. Some Investigations Regarding the Surface Treatment of Ultem*9085 Parts Manufactured with Fused Deposition Modeling. s.l. : Kunststofftechnik Paderborn (KTP), University of Paderborn, D-33102 Paderborn, Germany.

19. R. E. Williams, V. L. Melton. Abrasive flow finishing of stereo-lithography prototypes. Rapid Prototyping Journal. 1998, Vol. 4, 2.

20. Chil-Chyuan Kuo, Sheng-Jie Su. A simple method for improving surface quality of rapid prototype. Indian Journal of Engineering \& Material Sciences. 2013, Vol. 20.

21. Eric J. McCullough, Vamsi K. Yadavalli. Surface modification of fused deposition modeling ABS to enable rapid prototyping of biomedical microdevices. Surface modification of fused deposition modeling ABS to enable rapid prototyping of biomedical microdevices. 2013, Vol. 213, 6, pp. 947-954.

22. Shawn Moylan, John Slotwinski, April Cooke, Kevin Jurrens, M. Alkan Donmez. Proposal for a standardized test artifact for additive manufacturing machines and processes. Rapid Prototyping Journal. 1998, Vol. 4, 2. 
23. Makerbot.com. Makerbot.com. [Online] http://store.makerbot.com/replicator2x.

24. Mitutoyo. SJ-201P Datasheet. 